IFN Working Paper No. 1176, 2017

\title{
The Educated Underdog Becomes the Ultimate Superstar
}

Per Hjertstrand, Pehr-Johan Norbäck and Lars Persson 


\title{
The educated underdog becomes the ultimate superstar*
}

\author{
Per Hjertstrand \\ Research Institute of Industrial Economics \\ Pehr-Johan Norbäck \\ Research Institute of Industrial Economics \\ Lars Persson \\ Research Institute of Industrial Economics
}

June 2017

\begin{abstract}
We find an inverted relation between a player's birthday and the likelihood of receiving the Ballon d'Or (awarded to the best football player in the world). We develop a multi-period skill formation model with selection into elite education. We show that those born late (underdogs) need to work harder to be selected for elite educational programs. However, those born too late will not make the cut-off. Those born late - but not too late - will thus end up with the highest skill levels as adults (educated underdogs). We use detailed data on the performance of elite Swedish football players to illustrate our model. These data provide strong support for the predictions of the model.
\end{abstract}

\section{Introduction}

Who ultimately becomes a superstar? Malcolm Gladwell states in his bestselling book, David and Goliath, that underdogs can become superstars by turning their weaknesses into strengths. The basic idea is that underdogs need to work harder and try new strategies to compensate for their weaknesses. Many fail, but those who are successful can become extremely successful. How do institutions in the society then affect (i) who becomes an underdog, (ii) who remains an underdog, and (iii) who ultimately becomes a superstar? These issues are addressed in this paper.

We use data on football superstars to provide illustrations throughout this paper. Football is probably the most competitive activity in the world among young males over the last 50 years. The number of boys and men trying to become football stars is enormous, and the number of hours spent practising are staggering. For instance, in Sweden, $48 \%$ of all 9-year-old boys and 35\% of all 14-year-old boys played some form of organized football in $2015 .^{1,2}$

${ }^{*}$ We have greatly benefitted from comments from Magnus Henrekson, Henrik Horn, and from seminar participants at the CESifo Area Conference on Applied Microeconomics and IFN Stockholm. Financial support from the Jan Wallander Research Foundation, Marcus and Marianne Wallenberg Foundation and Vinnova is greatly acknowledged. Email addresses: per.hjertstrand@ifn.se; pehr.johan.norback@ifn.se; and lars.persson@ifn.se.

${ }^{1}$ Approximately 50,000 boys have been born each year in Sweden during recent decades. Of the approximately 25,000 9year-old players and 17,500 14-year-old players, only around 100 participated in national youth team practises and 1000 had the chance to play in youth clubs with excellent training. Eventually, approximately 60 will become elite players as adults (source: The Swedish Football Association, http://fogis.se/om-svff).

${ }^{2}$ In 2015, LinkedIn asked 8,000 professionals in the U.S. about their childhood dream jobs. More than $8 \%$ of all surveyed professionals stated that their childhood dream job was to become a professional or Olympic athlete. Other top childhood dream jobs included airplane or helicopter pilot, scientist, lawyer and astronaut. Approximately $30 \%$ of the surveyed professionals reported that they actually pursued their childhood aspiration (or a similar career). 
The most prestigious individual award in football is the "Ballon d'Or", which has been awarded annually since $1956 .^{3}$ Individuals born late in the year (i.e., late after the cut-off age for the football team) are physically disadvantaged as youth players, and therefore, we label them underdogs. In a first test of Gladwell's underdog hypothesis we examine whether Ballon d'Or winners (and nominees) are born later in the year than a random male from the population. Figure 1 contains the kernel density plots of the distribution of the birthdays of Ballon d'Or winners (solid red line) and both winners and nominees (dashed blue line). Overlaid is a histogram of the distribution of birthdays for the entire Swedish male population born during the period 1968-2010 (a proxy for the birthday distribution of the world male population).

Figure 1 reveals a bimodal birthday distribution with two distinct features: First, Ballon d'Or winners with birthdays in late summer and fall are highly overrepresented, and second, few winners are born very late in the year (i.e., the distribution falls rapidly towards the end of the year). This first observation supports Gladwell's original hypothesis, but the second rejects it.

Thus, Figures 1 and 2 suggest that players who are born later in the year - but not too late - become superstars. To determine why, we develop a skill formation model showing that children born late in the year will have incentives to work harder in order to be admitted in high-quality educational programs (elite teams) than children born earlier in the year. The reason is that children born later in the year have less age-related human capital to rely on as youth players. However, individuals who are born very late in the year will not have the capacity to pass the quality threshold. As they fail to be selected for high-quality teams, they quit playing elite football.

In our model, society selects children for high-quality educational programs. The skill development of each child will be higher in a high-quality program. This could be due to better instructors, better peers and a good reputation of the program leading to successful exit from the program. To be selected for and to remain in the high-quality program, a threshold skill level must be met. A crucial element of the model is that this youth skill level depends both on the skill acquired from previous effort exerted by the individual and on age-dependent human capital (for example, in football, having a heavier and more muscular body). However, the selection system does not distinguish between these different sources of observed skill. Following Cunha and Heckman (2007), we assume that skill formation is self-productive and complementary. That is, skill formation early in training is accumulated and leveraged in later periods; moreover, greater skill accumulation in a previous period improves the productivity of later investments.

At first, one might believe that self-productiveness and complementarity imply that the most advantaged child should accumulate the most skill and become a superstar as an adult. While there is such an effect in our model, there are also countering mechanisms that explain why those born later - but not too late ultimately become superstars. Children born later will exert more effort during early training compared to children born earlier in the year, since they cannot rely on age capital. This effect will be stronger for children who barely make it into the elite education program. This is the underdog incentive effect: individuals born late (underdogs) need to work harder to be admitted into high-quality programs.

However, children who are born too late will not find it worthwhile to try to enter a high-quality program, since the hurdle is so high. These players will exert low effort and receive low-quality educations (i.e., they will play for fun without aiming to become elite players). Thus, youth players who are born too late in the

\footnotetext{
${ }^{3}$ The Ballon d'Or was an annual association football award presented by France Football between 1956 and 2009 . Conceived by chief magazine writer Gabriel Hanot, the award honoured the player deemed to have the best performance over the previous year based on votes cast by Europe-based journalists. Originally, only European players could be considered for the Ballon d'Or, but in 1995, all players in European clubs became eligible. Every year, 3 players were nominated for the Ballon d'Or. The winner was chosen from among these three nominees.
} 


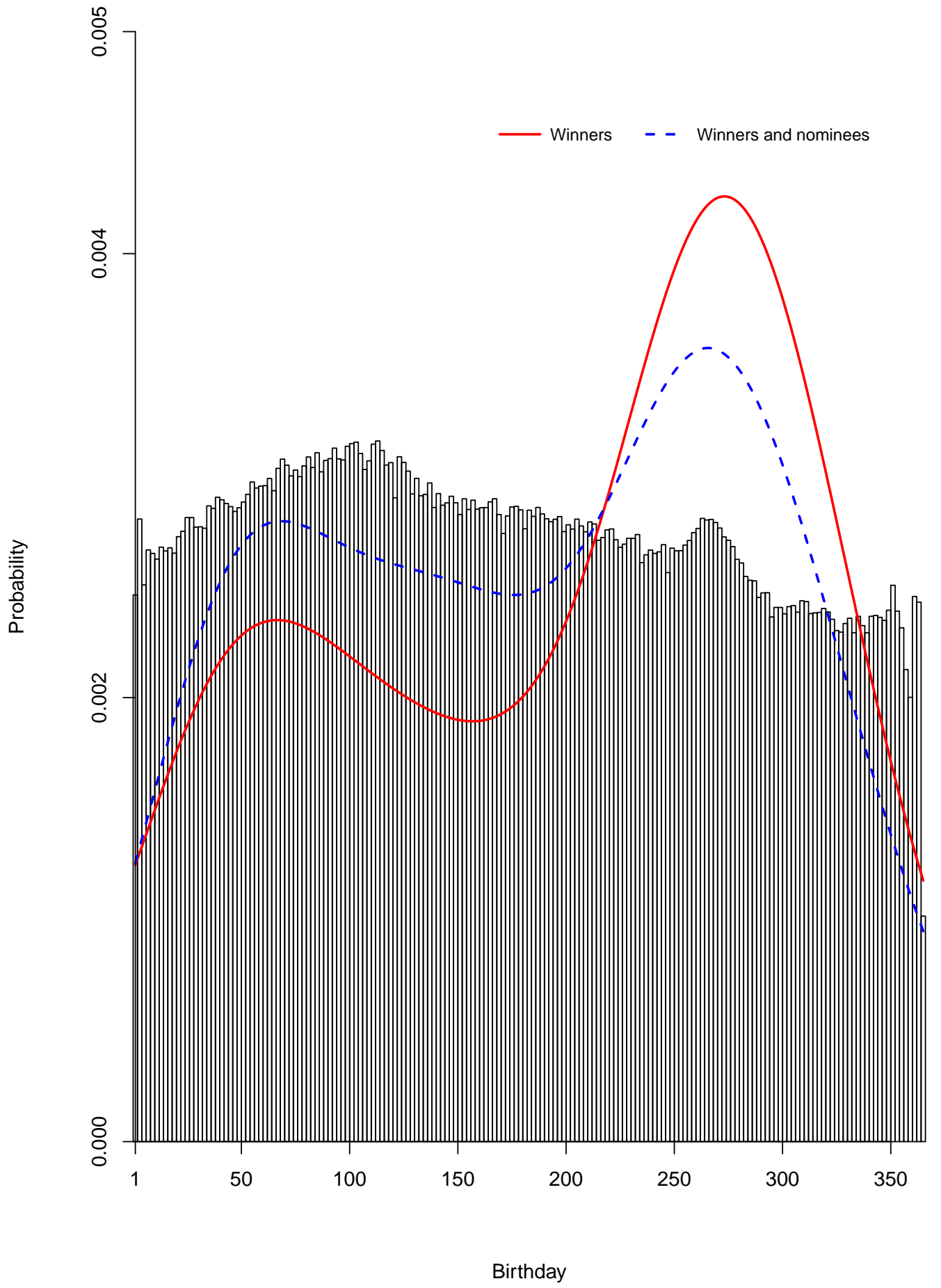

Figure 1: Kernel density plots of the birthdays of winners of Ballon d'Or and winners and nominees of Ballon d'Or. Overlaid is a histogram of the distribution of birthdays for the Swedish male population. 
year will have the lowest skill levels as adults.

Combining these two mechanisms implies that individuals born late - but not too late - in the year will be admitted to high-quality programs, where they can combine the skills gained from their higher training effort as youth players with high-quality training and education to ultimately become superstars. We refer to this as the educated underdog effect.

Why do individuals born earlier in the year, who are advantaged as youth players, not adjust their effort and train harder so that they can eventually become superstars? The key to understanding this result is that an underdog is forced to train harder than his unconstrained (first-best) effort to be selected by elite teams, while individuals born earlier in the year are not under such pressure.

We then consider the case in which complementarity between age capital and youth training is very strong and motivation less important. In this case, we find that players born early in the year might put in more effort as young players. They might then outperform players who are born later to ultimately become superstars. However, our empirical observations are consistent with the notion that motivation beats complementarity in football education.

As explained above, we use detailed data on elite and youth football players to provide a running illustration. There are several advantages of using Swedish data for this purpose. First, football clubs in Sweden have been part of a well-developed education system for youth players for the past 50 years, with well-educated and experienced coaches. Importantly, the selection criteria for elite teams at each level in the education system are transparent and known to each youth player. The cut-off date for participation is January 1 for both clubs and national teams.

Second, the Swedish Football Association ( $\mathrm{SvFF}$ ) coordinates national youth teams for boys in yearly cohorts for ages 15 to 19. Since these teams consist of the very best youth players in Sweden, it is fair to say that they are elite Swedish football teams. The final selection of players for national youth teams is purely exogenous (i.e., there should be little chance of self-selection), since it is conducted by the SvFF coaches.

Third, since 1946, one senior player has been selected for an annual national best player award. The player is chosen by a selection committee consisting of SvFF representatives and sports journalists from one of the largest newspapers in Sweden. Since all winners (but one) of the best player award have played on the senior Swedish national team, we can treat the sub-set of winners as a treatment group (within the entire set of national team players). In this case, the treatment is well-defined and clearly exogenous, since the player is chosen by an outside committee (with no chance of self-selection). Hence, the treatment effect (i.e., having been selected for the best player award) has a straightforward interpretation.

Fourth, we have data on the birthdays of all senior national team players since 1946 and youth players in the Swedish under 17 (U17) national team between 2010-2015. Moreover, we have obtained several other variables on each senior national team player, which we use as control variables in a regression analysis.

Finally, we have data on the birthdays of the entire male population in Sweden 1968-2010. Thus, assuming that the distribution of birthdays for the Swedish male population has remained rather constant since 1946, we have identified the correct comparison (control) group. This allow us to compare the birthday distributions of the elite youth players and the very best senior players with the birthday distribution of the general male population.

After placing the paper in the context of the literature in Section 2, we document three stylized facts about elite Swedish football in Section 3. First, we document strong relative age discrimination on youth national teams, which is consistent with the underdog selection effect. ${ }^{4}$ Second, we document the finding illustrated

\footnotetext{
${ }^{4}$ It should be noted that the SvFF is aware about the relative age discrimination in youth elite football. Since 2014 the
} 
in Figure 1: the very best players are born later in the year than a random male from the population. Using data on the birthdays of players who have won the best player award in Sweden, we essentially replicate the shape of the distribution of birthdays for the Ballon d'Or winners and winners of the best player awards in Figure 1. Third, we document the other finding illustrated in Figure 1 and found in the Swedish data: the very best senior players are rarely born very late in the year.

In Sections 4 and 5, we develop a model that provides an explanation for the observed stylized facts and that can be used to better understand how institutions affect incentives and outcomes in elite education. In section 6, we discuss some modifications and extensions of our model. In particular, we acknowledge that other countries may have different cut-off dates than January 1. Using data for the award of the best male football player in France and Germany, we also there find an overrepresentation of winners in the third quarter after the cut-off date. Section 7 concludes. Additional empirical results and all proofs are relegated to the Appendix.

\section{Related literature}

This paper contributes to the literature on the economics of child skill formation. The early theoretical literature on child development treats childhood as a single period (see, e.g., Becker and Tomes, 1986; Aiyagari et al., 2002; Bénabou, 2002). Building on more recent findings from the empirical literature on skill formation, a new literature has introduced models with several periods (see, e.g., Cunha et al., 2006; Cunha and Heckman, 2007). This literature emphasizes the importance of self-productivity and complementarity in children's skill formation. Self-productivity is the notion that skill attainment in one stage of the life cycle increases skill attainment in later stages of the life cycle. Complementarity suggests that early investment facilitates the productivity of later investment. Taken together, these effects imply that the returns to investing early in the life cycle are high. Moreover, the literature shows that for certain groups of children, mitigating disadvantages is more efficient than later intervention.

In our framework, individuals face constraints or hurdles that need to be overcome in order to obtain or take advantage of high-quality education. Individuals differ in the exogenous temporary abilities (relative age differences) that can be used to substitute for effort in producing skill. Importantly, these inherent abilities are temporary. Using this framework, we add to the literature by providing a number of results.

Children who are temporarily disadvantaged (e.g., those born late in the year) may end up the most skilled adults. Their temporary disadvantage pushes them to hard work as young people in order to access better education. This higher effort provision at an early age results in a higher adult skill level. That is, the initial temporary disadvantage in childhood becomes an advantage in adulthood. The higher effort needed to compensate for an early disadvantage, however, results in a lower expected utility over the entire life cycle. The barriers to elite education imply that youth players at excessive initial disadvantage (e.g., those born very early in the year) will give up on their ambition to obtain an education. However, we also show that if children discount the future too much compared to an "optimal" lifetime discount rate, then children with medium-level disadvantages may attain not only the highest skill level as adults but also the highest utility over the life cycle.

The paper also relates to the literature on the science of expertise. Several reviews (Ackerman, 2014; Er-

SvFF is also coordinating a future team. In the ordinary P15 and P16 national team a total of 66 players are selected and can participate. The future team consists of an additional 33 players that are born later in the year and are late into puberty (see http://fogis.se/arkiv/startsida/2016/04/i-future-team-far-talanger-tid/). 
icsson, 2007; Ericsson et al., 1993; Tucker and Collins, 2012), conclude that (sporting) expertise requires both deliberate practise and talent (both nurture and nature). These reviews refer to several studies documenting that engaging in intense physical training is associated with changes in muscle fibres and capillaries and in the size and structure of the heart. This literature shows that deliberate (planned and focused) training is correlated with high-quality (sport) performance. (e.g., Ericsson, 2008; Tucker and Collins, 2012). Moreover, these reviews suggest that heritable differences might influence the individual's capacity to engage in hard work (deliberate practice).

We add to this literature in two respects. First, to the best of our knowledge, we propose the first formal theoretical model wherein the individual makes a deliberate choice about the level of practise within an institutional setting. The model enables us to show that motivation, ability, and institutions interact to produce the final expertise of an individual. In particular, we show that higher motivation due temporary childhood disadvantages can result in the greatest expertise when combined with deliberate practise (elite education). Second, we provide empirical evidence from what is probably the most competitive sport (professional football) that talent is not all. The skewed distribution of football superstars compared to the cohort population provides evidence that institutions are important determinants of who ultimately becomes a superstar.

Our paper is also related to the economics of education literature on the impact of (relative) age and tracking of long-term performance. Angrist and Krueger (1992) examines how the season of birth affects educational attainment. Using Norwegian data, Black et al. (2011) find that the long-run effects of school starting age on education and earnings are modest. Using Swedish data, Fredriksson and Öckert (2014) found that an older school starting age implies an increased educational attainment. They also show that a comprehensive school reform in Sweden (which postponed tracking until age 16) reduced the effect of the school starting age on educational attainment. Moreover, they found no effect on prime-age earnings on average, but for individuals with less-educated parents, they find that prime-age earnings increase in response to the school starting age. Dustmann et al. (2016) find no evidence that, for these students, following an advanced track leads to more favourable long-term outcomes. They attribute this result to the up- and downgrading of students across tracks after middle school when more information about their potential is available.

We add to this literature in two main ways: First, we study top performance in an extremely competitive activity outside the schooling system, football. We find an inverted relation between the player's birthday and the likelihood of becoming among the very best players. Second, we develop a multi-period skill formation model with selection into elite education. This enable us to explain that a temporary disadvantage can generate superior long-run performance through increases in effort. ${ }^{5}$

Finally, this paper is related to the sports science literature on the so-called relative age effect (RAE), which has shown that players born early in the year are overrepresented on elite youth teams (See Musch and Grondin, 2001, for a review on the RAE in sports). Stylized fact 1 documents a strong RAE for the Swedish U17 team. However, recently, Gibbs et al. (2012), and Bryson et al. (2014) have found that players born later in the year might perform better in the long run. Closely related to our study is that of Ashworth and Heyndels (2007), which provides a theoretical graphical analysis of the effects of selection and peer influence

\footnotetext{
${ }^{5}$ There is a small theoretical literature on tracking. Lazear (2001) considers the production decision in a model of educational output. Epple et al. (2002) offer a model of tracking as an equilibrium political economy response to the threat of exit (private school) by rich parents. Morgan et al. (2013) propose a model wherein individuals have different skills before beginning formal education due to differences in early childhood development. They show that colour-blind tracking underplaces minorities. Therefore, in expectation, minority students will have higher abilities than non-minority students assigned to the same track.

We differ by examining how temporary disadvantages affect incentives to exert effort to gain access to high-quality education programs.
} 
on the performance of football players. Using data on German football players, they estimate an earnings function for players in the 1997-1998 and 1998-1999 seasons, and they find evidence of a birth-month-related wage bias. That is, players born late after the cut-off date earn higher wages. Our contribution to this literature is two-fold. To the best of our knowledge, we propose the first micro-founded skill-formation model of football education, including temporary advantages, selection and endogenous training. We show that players born later in the year will, in equilibrium, exert more effort and therefore accumulate more skill (i.e., there is an underdog incentive effect), while players born very late in the year find that the effort needed for admittance into elite training groups to be excessively high. These effects imply an inverse relation between the player's final football skill and the player's birthday. ${ }^{6}$

\section{Stylized facts}

This section documents some stylized facts using our running illustration, elite training and education in football. For this purpose, we analyse the distributions of birthdays of football players and of the general male population using detailed Swedish data. In the next section, we develop a model that provides an explanation for the observed stylized facts and that can be used to better understand how institutions affect incentives and outcomes in elite education.

\subsection{The population}

We obtained data on males born in Sweden each day over the years 1968-2010 from Statistics Sweden (leap years excluded). Table 1 provides summary statistics. The median birthday is day 172 (i.e., June 20). The results for the 1st quartile (25th percentile) and 3rd quartile (75th percentile) indicate that $25 \%$ and $75 \%$ of all males were born on or before day 88 (March 28) and 263 (September 19), respectively.

\begin{tabular}{lcccccccc}
\hline \hline & & \multicolumn{7}{c}{ Summary statistic } \\
\cline { 3 - 9 } Data sample & \# obs. & min & 1st quartile & median & 3rd quartile & max & mean & std. dev. \\
\hline \multirow{2}{*nnyyyyyy}{ Population } & $1,706,304$ & 1 & 88 & 172 & 263 & 365 & 176.1 & 102.9 \\
U17 & 186 & 2 & 44.5 & 110 & 125 & 362 & 125.0 & 93.5 \\
National team & 650 & 1 & 74 & 153 & 266.5 & 365 & 167.3 & 109.1 \\
"Stora grabbar" & 299 & 1 & 80.5 & 167 & 268.5 & 363 & 173.2 & 104.2 \\
"Guldbollen" & 53 & 2 & 80 & 214 & 279 & 353 & 186.6 & 106.1 \\
\hline \hline
\end{tabular}

Table 1: Descriptive statistics of birthday distributions

The overlaid histogram in Figure 2 plots the full distribution for the sample of 1,706,304 males born over this period. This histogram illustrates a previously documented and well-known fact about the Swedish

\footnotetext{
${ }^{6}$ By looking more closely at some recent studies in sports economics, we find that other studies also reveal an inverted relation between birthday and success. Ashworth and Heyndels (2007) find lower salaries for players born in the last two months of the year. Fumarco (2015) used a sample of football players in the Italian Series A and find that players born relatively late in an age group receive lower gross wages than players born earlier. He mostly attributes these results to the players born in the December cohort (see also, Gibbs et al., 2012, and Bryson et al., 2014). This suggests that the discrimination hurdle is indeed important to explaining the overachievement effect and that general peer effects alone are insufficient to explain this phenomenon.
} 


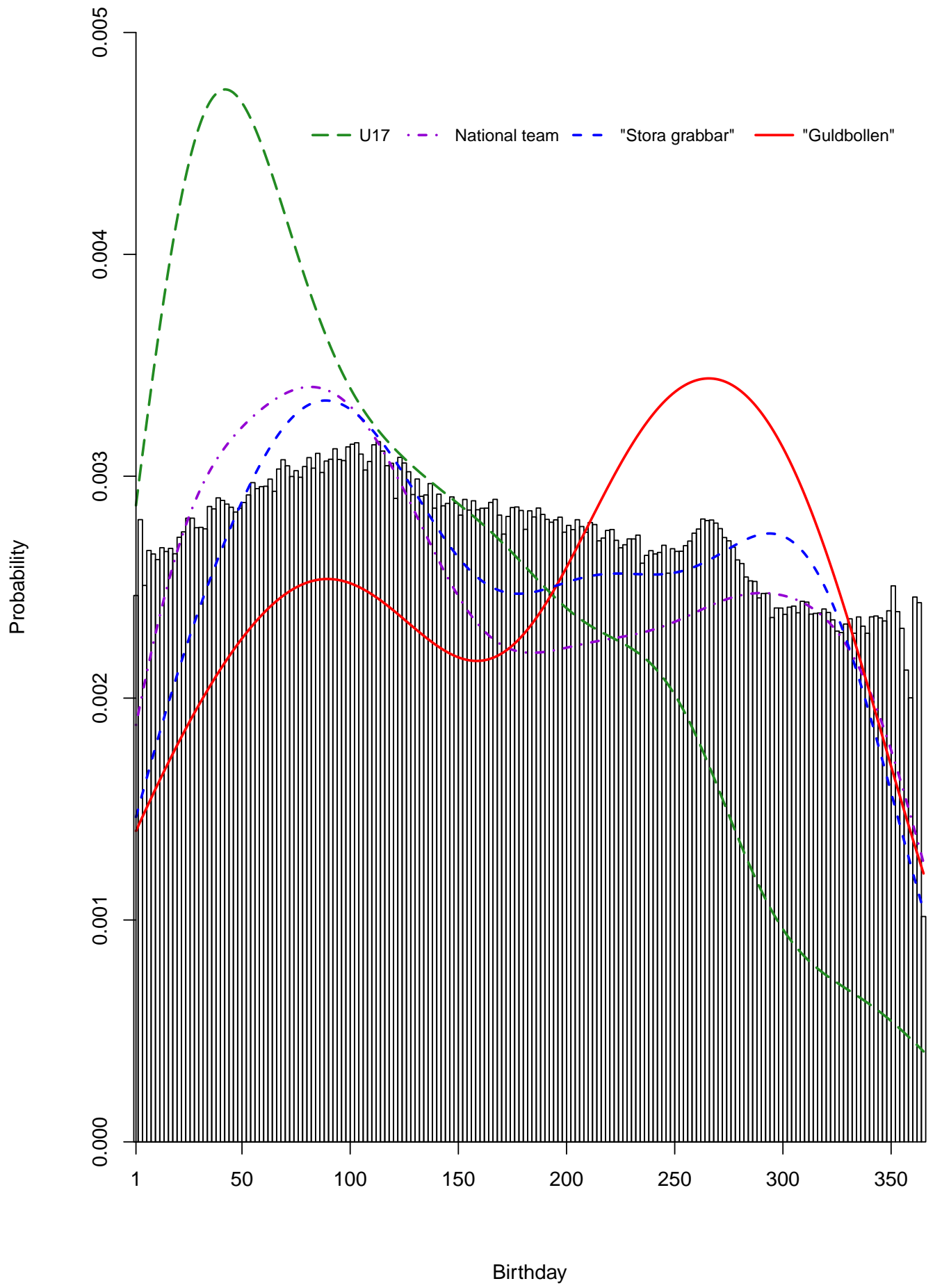

Figure 2: Kernel plots of the distribution of birthdays for under 17 (U17) players, national team players, winners of the "Guldbollen" award and winners of the "Stora grabbar" award. Overlaid is a histogram of the distribution of birthdays for the Swedish male population. 
population: Most babies are born in early/mid April, after which the birth rate decreases until September when it increases slightly and reaches a secondary mode in late September/early October. ${ }^{7}$ The most likely day to be born, that is, the mode (highest peak) of the distribution, is reported in Table 2 and is estimated to be day 101 (April 10). These distributional features can be explained by the fact that most babies are conceived during the summer holidays (yielding the primary mode in April) and during the Christmas/winter holidays (explaining the secondary mode in September/October).

\begin{tabular}{lcclc}
\hline \hline \multirow{2}{*}{ Data sample } & \multicolumn{2}{c}{ Highest mode (peak) } & & Silverman test \\
\cline { 2 - 3 } Population & Day & Std. dev. & & p-value \\
\hline U17 & 101.4 & 3.2 & & $\mathrm{n} / \mathrm{a}$ \\
National team & 81.5 & 15.6 & & 0.721 \\
"Stora grabbar" & 88.6 & 15.6 & & $0.001^{* * *}$ \\
"Guldbollen" & 266.0 & 62.4 & & $0.011^{* *}$ \\
\hline \hline
\end{tabular}

Notes: The hypothesis in the Silverman test is $\mathrm{H}_{0}$ : Distribution is unimodal, against, $\mathrm{H}_{1}$ : Distribution is at least bimodal. Appendix C provides a brief description of the Silverman test. ${ }^{* * *}$ and ${ }^{* *}$ show significance at the $1 \%$ and $5 \%$ nominal significance levels.

Table 2: The highest mode (peak) and Silverman test

\subsection{The under 17 national team players}

The $\mathrm{SvFF}^{8}$ coordinates national youth teams for boys in yearly cohorts for ages 15 to 19 . We collected data on the birthday and birth year of every player on the U17 team between 2010 and 2015. We have a total of 186 observations.

Table 1 provides strong evidence of an RAE in the data. First, the median birthday for U17 players is day 110 (April 19), which is more than 60 days earlier than the median birthday in the general male population. Second, the results for the 3rd quartile indicate that $75 \%$ of all U17 players are born earlier than day 125 (May 4). Third, the relatively low standard deviation suggests that the birthdays are clustered in early spring. Given these results, we arrive at our first stylized fact.

Stylized fact 1: There exists a strong RAE in elite youth football in Sweden. That is, individuals who are born early in the year are overrepresented on the Swedish U17 team.

To provide additional evidence of a strong RAE in the data, Table 3 presents several measures of skewness for the birthday distributions of the population and the U17 players.

\footnotetext{
${ }^{7} \mathrm{~A}$ Kolmogorov-Smirnov test of the null that the distribution is uniformly distributed is clearly rejected (p-value $\left.<0.001\right)$.

${ }^{8}$ www.svenskfotboll.se/in-english/
} 


\begin{tabular}{lcccc}
\hline \hline & \multicolumn{4}{c}{ Measures of skewness } \\
\cline { 2 - 5 } Data sample & "Standard" & Bowley & Groeneveld \& Meeden & Pearson \\
\hline \multirow{2}{*}{ Population } & 0.09 & 0.04 & 0.05 & 0.04 \\
U17 & 0.61 & 0.10 & 0.19 & 0.16 \\
National team & 0.20 & 0.18 & 0.15 & 0.13 \\
"Stora grabbar" & 0.10 & 0.08 & 0.07 & 0.06 \\
"Guldbollen" & -0.24 & -0.35 & -0.30 & -0.26 \\
\hline \hline
\end{tabular}

Notes: "Standard" is the usual measure of skewness. Appendix C provides a brief description of the measures of skewness (See also Kim and White, 2004).

Table 3: Measures of skewness

These results show that the distribution of birthdays for U17 players is asymmetric around its mean and median. The positive measures imply that the distribution is skewed to the right and, thus, has a larger concentration of mass to the right (i.e., there is a higher probability that a U17 player is born earlier rather than later in the year). As further seen from Table 3, the distribution is considerably more right skewed than the distribution of the general male population.

Finally, Table 2 reports the estimated values and number of modes (i.e., peaks) of the distribution. The primary mode (highest peak) corresponds to the most probable birthday, which is estimated to occur on day 42 (February 11) for U17 players. This is considerably earlier than the mode for the general male population, which was day 101 (April 10). A Silverman test shows that the distribution of U17 players' birthdays is unimodal. These results contribute to a large body of evidence of a strong RAE in elite youth sports; see Musch and Grondin (2001) for a detailed review.

\subsection{The national team players}

We also obtained data on all senior national team players in Sweden from 1946 to 2015. These data include the birthdays of all 650 players and the following variables: (i) their main position on the field; (ii) whether they played in an international (i.e., non-Swedish) league during their football career; (iii) age when they debuted in the senior national team; and (iv) a measure of national team performance during the years in which they played on the team. Table A1 in the appendix gives a more detailed description of these variables.

Table 1 above shows that the median birthday for national team players is 20 days earlier than the median birthday of the male population, indicating the presence of a weak RAE. This is also suggested by the positive measures of skewness reported in Table 3, which imply that the distribution is skewed to the right (and is seemingly more skewed than that of the population). The kernel density plot in Figure 2 shows that the distribution is skewed and weakly bimodal. It has the highest mode at day 81 (March 21, see Table 2), after which the number of births decreases sharply until mid-year when it increases slightly and reaches a secondary mode in mid- to late October.

Table 2 also report the results of a Silverman test, which reject the null that the distribution is unimodal and favours a bimodal distribution. Compared to the male population, the distribution has considerably more mass later in the year. This implies that national team players are more likely to have been born in early spring or in October than a random male from the population. 


\subsection{The Stora Grabbar award}

If a player on the national team collects a certain number of points by participating in international matches and major tournaments, such as the World and European Championships, he is given a "Stora Grabbars Märke". ${ }^{9}$ Because players are chosen by the manager of the national team, we believe it is fair to assume that selection is exogenous. Accordingly, we proceed by interpreting the national team players who have received the Stora Grabbar award as a treatment group (within the set of national team players).

We extracted the birthdays and birth years of national team players who have received the Stora Grabbar award, yielding a total of 299 observations. From the summary statistics in Table 1, we see that the median birthday is 14 days later than that of all national team players and only 5 days earlier than that of the general population. Together with the measures of skewness in Table 3, this finding suggests that the birthday distribution of Stora Grabbar winners is similar to the distribution of the general population.

Players who receive the Stora Grabbar award are among the most experienced and successful of all players on the national team (in terms of the number of international matches and participation in major tournaments). It therefore seem fair to say that these are players with high quality. Our descriptive analysis thus shows that players of high quality are born later in the year than are lower quality players (i.e., players who do not win this award). However, this analysis does not control for other factors that might explain why some players receive the Stora Grabbar award. We therefore perform a regression analysis using the variables (i)-(iv) described in the previous section as control variables (see Table A1 in the appendix for a detailed description). We use a binary measure of the Stora Grabbar as our dependent variable. The log of the birthday and all the control variables are our independent variables (including a constant). The probit estimation results, as marginal effects, are given in Table A2 in the appendix.

Our main variable of interest, $\ln$ (Birthday), is significant at the $1 \%$ level. Its estimated marginal effect indicates that if a national team player is born 1\%, i.e., 3.65 days, later in the year, then he has a $3.7 \%$ higher probability of receiving the Stora Grabbar award. Thus, even after controlling for other variables, this result suggests that being born later in the year increases the quality of the player. Other significant variables include whether he ever played in an international league (which increases the probability of receiving the award by $5.7 \%$ ), the age at which he debuted in the national team (a debut $1 \%$ sooner increases the probability of receiving the award by $39.4 \%$ ), and finally, how well the national team performed during the period in which he was on the team (an additional goal scored by the team increases the probability of receiving the award by $1.7 \%$ ).

\subsection{The best player award - the Guldbollen}

A prize for the best male player, called the "Guldbollen" ${ }^{10}$, has been awarded in Sweden since 1946. One Swedish player (from the domestic or an international league) is chosen each year by a committee consisting of representatives from the SvFF and sports journalists from one of the largest newspapers in Sweden. All but one of the selected players has played on the Swedish national team. Consequently, we interpret the winners as a treatment group (within the entire set of national team players). Because the winner is chosen by an outside committee, thus eliminating the possibility of self-selection, we believe that it is valid to assume that the treatment is exogenous.

\footnotetext{
${ }^{9}$ The name of this award translates to "the big boys badge".

${ }^{10}$ The name of this award literally translates to "the golden ball". The award is conferred in an official ceremony that is broadcast on Swedish national TV.
} 
We gathered data on the birthdays and birth years of all Guldbollen winners, yielding a total of 70 observations. Because a few players have received the award more than once, we omit multiple observations of the same player to obtain a final sample of 53 observations. ${ }^{11}$ Table 1 shows that the median birthday of Guldbollen winners is day 214 (August 1), which is 44 days later than that of the general population. Moreover, Table 3 shows that in contrast to U17 players, the general population and national team players, the birthday distribution of Guldbollen winners is skewed to the left (not to the right). This pattern can also be observed in the kernel density plot in Figure 3, which shows that the distribution is bimodal with a secondary mode in early to mid-April and a primary mode on day 266 (September 22, see Table 2), implying that Guldbollen winners are more likely to have been born in September/October than in the spring. ${ }^{12}$ In fact, the primary mode coincides with the primary mode of the birthday distribution of Ballon d'Or winners (c.f. Figure 1). Thus, Ballon d'Or and Guldbollen winners are likely to be born on nearly the same day.

As seen in Figure 2, the birthday distribution of Guldbollen winners is inversely related to the birthday distributions of the general population, national team players and Stora Grabbar winners. This reveals an interesting pattern: If we classify a national team player who has been awarded a Stora Grabbars Märke as a higher quality player than one without an award but a lower quality player than one with a Guldbollen, we obtain a categorical scale in terms of quality, where national team players without awards are of "low" quality, players with Stora Grabbars Märke are of "medium" quality and Guldbollen winners are of "top" quality. If we compare the birthday distributions for these three categories, we see that, as the quality of the players increases, the distribution progressively shifts to the left, with more mass later in the year (which is consistent with the measures of skewness reported in Table 2). Thus, as the quality of the players increases, we observe an increasingly inverted RAE. We document this as a second stylized fact.

Stylized fact 2: There exists an inverted RAE among the very best football players in Sweden (i.e., winners of the Guldbollen). That is, players born later in the year (but not too late) are overrepresented (relative to the general population) among the best-prize-winning - football players in Sweden.

To further illustrate this stylized fact, we computed the expected number of Guldbollen winners using the birth probabilities from the male population each month as weights and subtracted this number from the actual number of winners. This yields the difference between the actual and the expected outcome each month, conditional on the birthday distribution of the population. The results are represented in the red bars in Figure 3, where upward sloping (downward sloping) bars indicate more (fewer) actual winners than expected.

With the exceptions of January and March, we see that the months from January to August have fewer winners than predicted based on the population. (However, notice that January and March have only a slight excess of actual winners). These results confirm what we observed in the kernel density plots in Figure 2: a Guldbollen winner is less likely to be born in the spring/summer than is a random male in the general population. As further documented in Stylized fact 2, considerable more winners are born later in the year (i.e., from August to November).

As a mean of comparison, the blue bars in Figure 2 reflect the same computations for the U17 players.

\footnotetext{
${ }^{11}$ We also performed this analysis on the entire sample of 70 observations. The results of this analysis provide even stronger evidence for our stylized facts. It is easy to understand why: although 8 players have won the award twice, one player, born on October 3, has won the award 10 times. Thus, the birthday of this player receives 10 times the weight of a player who has received the award once, which shifts the birthday distribution further to the left. In this case, the month of October has even more winners than expected.

${ }^{12}$ Table 2 reports a Silverman test that rejects a unimodal distribution in favour of one that is bimodal.
} 


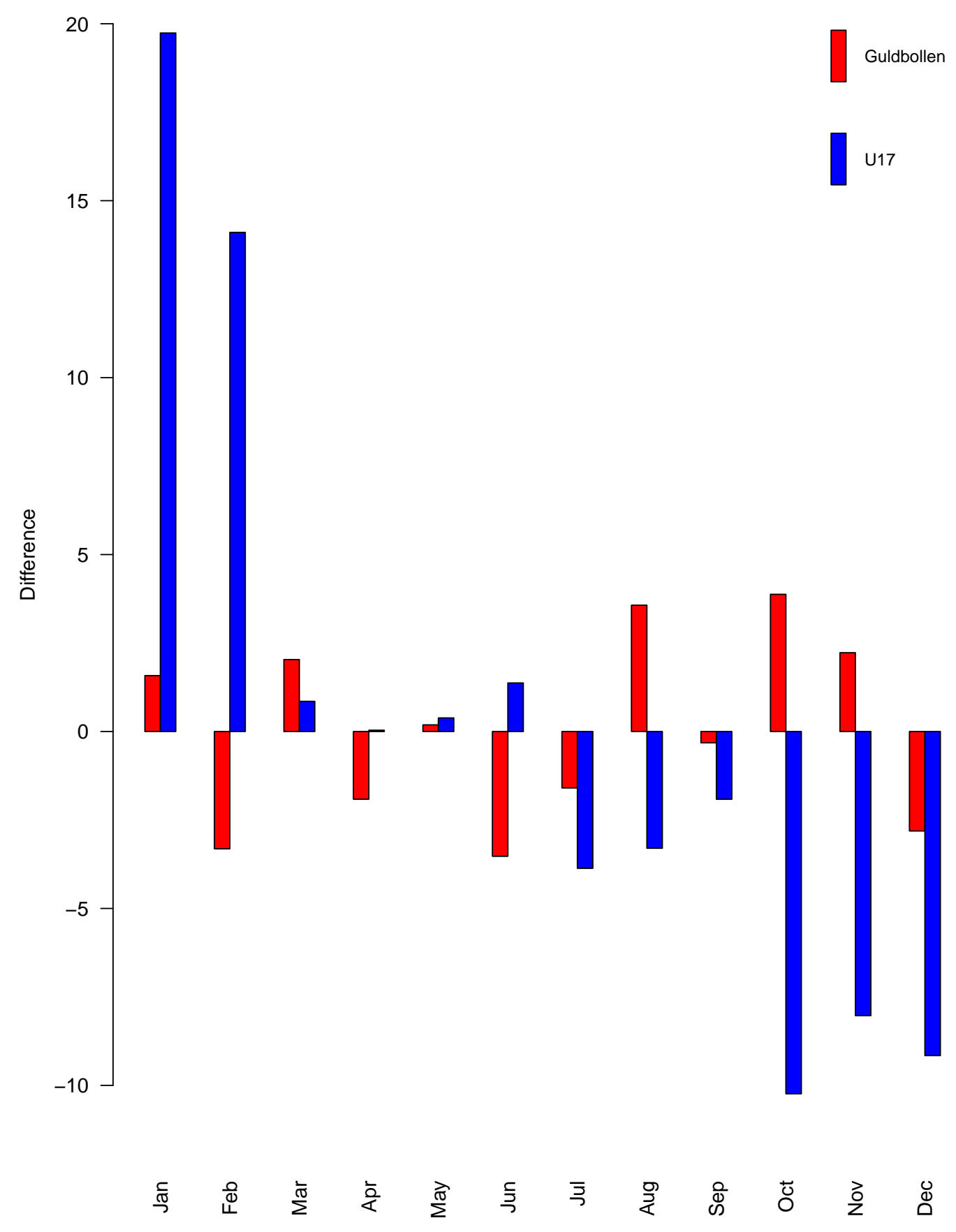

Figure 3: Difference between actual and expected amount of "Guldbollen" winners and of under 17 (U17) players each month. 
The upward sloping bars from January to March and the downward sloping bars from July to December illustrate a strong RAE among these players (i.e., Stylized fact 1).

Figure 3 illustrates yet another distinctive feature of the birthday distribution of Guldbollen winners: There are few winners born very late in the year. This pattern can also be seen in the kernel density plots in Figure 2: While the birthday distribution of the general population moderately declines at the end of the year, there is a very sharp decline in the birthday distribution of Guldbollen winners. Collectively, Figures 2 and 3 show that there is a considerably lower probability that a Guldbollen winner is born at the very end of the year than a male in the general population. We document this as a third stylized fact.

Stylized fact 3: Players born very late in the year are underrepresented (relative to the general population) among winners of the best football player in Sweden award (i.e., the Guldbollen).

We complement the descriptive analysis with a regression analysis using the variables (i)-(iv) described in the two previous sections as controls (see also, Table A1 in the appendix). Table A2 reports the marginal effects from a probit estimation using the binary measure Guldbollen as the dependent variable and $\ln$ (Birthday) and the controls (including a constant) as the independent variables. Being born $1 \%$ later (3.65 days) increases the probability of being awarded the Guldbollen by almost 1\%. As expected from the very low mean of the binary dependent variable (only $8 \%$ of all 650 national team players have received the Guldbollen award), there are very few significant variables in this model.

We also run quantile regressions to estimate the treatment effect $\gamma$ from the treatment model:

$$
\text { Birthday }_{i}=\gamma \times \text { Guldbollen }_{i}+\beta \times \mathbf{x}_{i}+\varepsilon_{i},
$$

for all national team players $i=1, \ldots, 650$, where $\mathbf{x}$ is the same set of controls (including a constant) as in the probit estimations (to avoid endogeneity issues due to omitted variables). The estimate of $\gamma$ gives a measure (in days) of how much later in the year a winner of the Guldbollen award is born relative to players who have not won the award. We estimate the treatment model at all nodes in an equally spaced grid with increments of 0.05 , ranging from 0.05 to 0.95 . The parameter $\gamma$ is significant at three quantiles. The median effect (quantile 0.5) shows that a Guldbollen winner is born 52.363 days later than a player that does not win this award. This result provides further evidence in support of Stylized fact 2, and it is very close to the descriptive results reported in Table 1, which estimated an unconditional median effect of $61(=214-153)$ days. Consistent with Stylized fact 3, we find a significant negative effect for players born very late in the year. Specifically, for the 0.9 and 0.95 quantiles, we find that Guldbollen winners are born earlier by 18.568 and 12.837 days, respectively, than non-winners.

Having established these stylized facts, we now provide a theory that can explain these facts and that can be used to better understand how institutions affect incentives and outcomes in elite education.

\section{The model}

Consider a continuum of young people in the same age cohort that derives utility from success in football. The interaction is illustrated in Figure 4. A player faces the following utility maximization problem: 


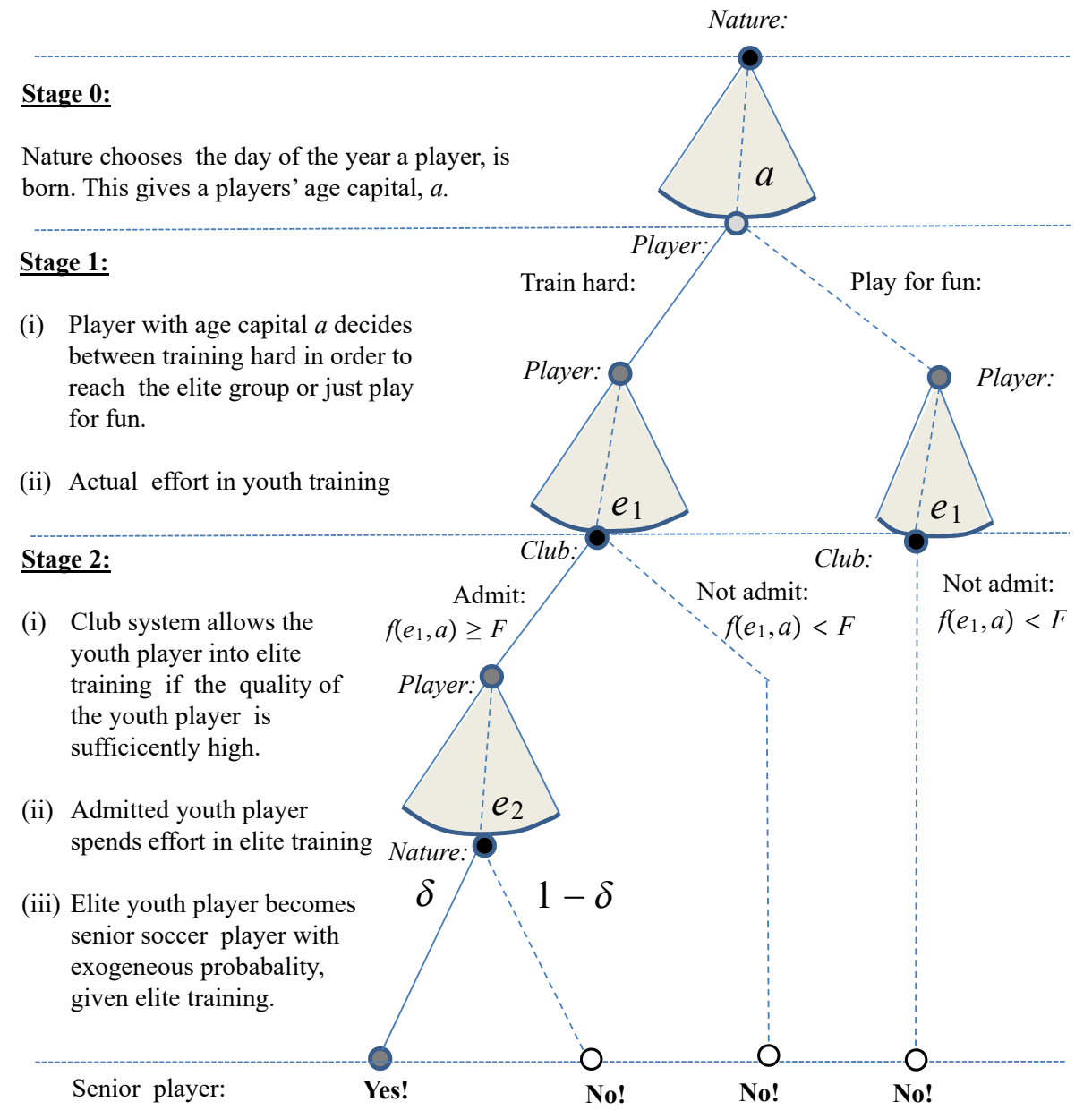

Figure 4: The effort choices. 


$$
\begin{aligned}
\max _{\left\{e_{1}, e_{2}\right\}} & : \quad U\left(e_{1}, e_{2}\right)=\underbrace{u\left(f\left(e_{1}, a\right)\right)-C_{1}\left(e_{1}\right)}_{\text {Net utility as a youth player }}+\underbrace{\delta \cdot v\left(g\left(e_{1}, e_{2}\right)\right)-C_{2}\left(e_{2}\right),}_{\text {Expected net utility as an elite player }} \\
\text { s.t } & : \underbrace{f\left(e_{1}, a\right) \geq F}_{\text {Participation constraint for elite football }} \\
\text { s.t } & : \underbrace{U\left(e_{1}, e_{2}\right) \geq \widetilde{U}(a)=\max _{\text {plite program constraint }}\left[u\left(f\left(e_{1}, a\right)\right)-C_{1}\left(e_{1}\right)\right]}_{e_{1}},
\end{aligned}
$$

where the notation (to be explained below) is: ${ }^{13}$

\begin{tabular}{lllll}
\multicolumn{2}{l}{ Youth (Stage 1) } & & Elite (Stage 2) \\
\cline { 1 - 2 }$e_{1}:$ & Effort as a youth player & & $e_{2}:$ & Effort as an elite player \\
$C_{1}\left(e_{1}\right):$ & Cost of effort as a youth player & & $C_{2}\left(e_{2}\right):$ & Cost of effort as an elite player \\
$a:$ & Age capital & & $\delta:$ & Probability of exiting the elite program as professional \\
$f\left(e_{1}, a\right):$ & Quality as a youth player & & $g\left(e_{1}, e_{2}\right):$ & Quality as an elite player \\
$u(\cdot):$ & Utility function as a youth player & $v(\cdot):$ & Utility function as an elite player \\
\hline
\end{tabular}

Stage 0: Age capital. In the initial stage, nature picks the day of the year on which the individual is born. This date determines the player's age capital, $a \in\left(0, a^{\max }\right)$. That is, a player has more age capital the earlier in the year he is born. Ceteris paribus, a player with a more age capital is assumed to be a more successful youth player. This is captured by assuming that, for a given amount of youth training, $e_{1}, y o u t h$ player quality $f$ is increasing in the age of the youth player, i.e., $f_{a}^{\prime}\left(e_{1}, a\right)>0$. This assumption mirrors the fact that youth players born earlier in the year are more physically and mentally developed than players born later in the year.

Stage 1: Effort in youth training. In Stage 1, the youth player decides whether he (or she) will aim to participate in the elite program in Stage 2 or to just play for fun, in which case, he will only be active as a youth player. If he plays for fun, he expends effort $e_{1}>0$ in youth training and maximizes his net utility as a youth player $u\left(f\left(e_{1}, a\right)\right)-C_{1}\left(e_{1}\right)$, where we assume that youth quality $f\left(e_{1}, a\right) \geq 0$ is also strictly increasing and strictly concave in training effort $e_{1}$, i.e., $f_{e_{1}}^{\prime}>0$ and $f_{e_{1} e_{1}}^{\prime \prime}<0$, with $f(0, a)=0$. Youth utility $u(f(\cdot))$ is, in turn, strictly increasing and strictly concave in youth quality, i.e., $u_{f}^{\prime}>0$ and $u_{f f}^{\prime \prime}<0$. Importantly, youth training is associated with a cost $C_{1}\left(e_{1}\right)$, which is strictly increasing and strictly convex, i.e., $C_{1}^{\prime}\left(e_{1}\right)>0, C_{1}^{\prime \prime}\left(e_{1}\right)>0$, with $C_{1}(0)=0$. Choosing to play only youth football and rejecting the elite program yields the indirect utility $\widetilde{U}(a)=\max _{e_{1}}\left[u\left(f\left(e_{1}, a\right)\right)-C_{1}\left(e_{1}\right)\right]$.

A youth a player becomes more successful by exerting effort $f_{e_{1}}^{\prime}>0$. This will also make him more likely to be admitted into an elite program. It is only by participating in an elite training program that he can become an adult elite senior player. This may, for example, be due to the better instructors and/or higherquality peers of the elite program. ${ }^{14}$ However, there are a limited number of seats in the elite program. This

\footnotetext{
${ }^{13}$ In the model, we have simplified the notation such that youth quality in Stage 1 is given by the function $S_{1}=f\left(e_{1}, a\right)$ and that the quality as an elite player in Stage 2 is given by $S_{2}=g\left(e_{1}, e_{2}\right)$. Thus, stage 2 quality directly depends on effort in period $1 e_{1}$. To save on notation, we omit $S_{1}$ and $S_{2}$ and use the quality functions $f($.$) and g($.$) directly.$

${ }^{14}$ Research on the science of expertise has shown that individuals who spend a sufficiently high amount of effort can develop strong skills (e.g., in music, sports). However, the quality of training also matters (i.e., deliberate practise). In this paper, we assume that it is only when qualified trainers and programs are available that intensive training is effective. (See, for instance, the references in Ericsson and Pool, 2016).
} 
implies a quality threshold that a youth player needs to reach in order to be accepted into elite training, as the managers of elite teams has strong incentives to win matches.

Thus, a player is only admitted into an elite youth program if his quality is above some threshold $F$, that is, $f\left(e_{1}, a\right) \geq F$. If the player is admitted, the skills formed through training effort as a youth player in Stage 1 will persist in Stage 2. We capture this by assuming that the quality as an elite player in Stage $2, g\left(e_{1}, e_{2}\right) \geq 0$, for a given amount of effort in elite training $e_{2}$, is strictly increasing and strictly concave in youth effort $e_{1}$, i.e., $g_{e_{1}}^{\prime}>0$ and $g_{e_{1} e_{1}}^{\prime \prime}<0$. Cunha and Heckman (2007) explain that allowing the skills acquired in one period to persist in future periods is important in skill-formation models. They refer to this property as self-productivity.

The youth player thus internalizes that he - as an elite player - will draw an expected net utility $\delta \cdot v\left(g\left(e_{1}, e_{2}\right)\right)$ from his elite quality $g$. The utility function $v(g(\cdot))$ as an elite is strictly increasing and strictly concave in quality $g$, i.e., $v_{g}^{\prime}>0, v_{g g}^{\prime \prime}<0$, with $v(0)=0$. As illustrated in Figure $4, \delta$ is an (exogenous) probability that the player becomes a professional senior player at the end of Stage 2. This reflects the fact that injuries and other obstacles may end a player's participation in the elite program (eliminating any chance of an elite senior career). ${ }^{15}$ An alternative interpretation is that $\delta$ is a discount factor. ${ }^{16}$

A key feature in our model is how the age capital $a$ impacts player quality. We thus assume that youth player quality $f$ is increasing in the age of the youth player, i.e., $f_{a}^{\prime}\left(e_{1}, a\right)>0$, which captures the fact that youth players born early in the year are more physically and mentally developed than players born later in the year. We also allow our model to capture the fact that older players may benefit from complementarity between age capital and training effort, i.e., $f_{e_{1} a}^{\prime \prime} \geq 0 .{ }^{17}$ However, in Stage 2, we assume that age capital a has no effect on elite player quality $g$ other than through its potential indirect impact on youth effort and elite effort, $e_{1}$ and $e_{2}$, respectively. This assumption captures the fact that the direct advantage of being born early in the year decreases with player age and as maturity differences diminish.

In Section 6, we discuss how the results change with other assumptions. One alternative is to have youth player quality enter directly into elite player quality, $g\left(f\left(e_{1}, a\right), e_{2}\right)$. However, age capital would then be effective even in adulthood, which seems questionable. In another specification age capital would have only an indirect effect through its impact on youth training, $g\left(f\left(e_{1}\right), e_{2}\right)$.

Stage 2: Effort in elite training. In Stage 2, given that his youth quality is high enough to gain admission into the elite program, $f\left(e_{1}, a\right) \geq F$, he expends elite training effort $e_{2}$ to increase his elite quality $g\left(e_{1}, e_{2}\right)$. We assume that $g$ is strictly increasing and strictly concave in $e_{2}$, i.e., $g_{e_{2}}^{\prime}>0$ and $g_{e_{2} e_{2}}^{\prime \prime}<0$, with $g\left(e_{1}, 0\right)=0$. To allow for the fact that skills produced in one stage may improve the productivity of investments made in subsequent stages, we assume that youth effort and elite effort $e_{1}$ and $e_{2}$, respectively, are complementary, i.e., $g_{e_{1} e_{2}}^{\prime \prime} \geq 0$. This corresponds to what Cunha and Heckman (2007) call dynamic complementarity. ${ }^{18}$

\footnotetext{
${ }^{15}$ We expect this probability to be fairly low since few youth athletes actually become professional athletes. In the U.S. alone, there are currently only approximately 12,450 professional athletes (Source: "What Common Dream Jobs Actually Pay", J. Smith, Forbes magazine, Dec 13, 2013).

${ }^{16}$ Thus, without loss of generality, we assume that an elite youth player who is injured and cannot complete elite football training obtains a utility of zero in Stage 2 (this occurs with probability $1-\delta$ ). We can easily allow for elite youth players who do not become senior players to receive utility from participation in the elite training program.

${ }^{17}$ Reversing this assumption, i.e., $f_{e_{1} a}^{\prime \prime}<0$, would strengthen our main results and make them simpler to derive.

${ }^{18}$ In the model, we have simplified the notation such that youth quality in Stage 1 is given by the function $S_{1}=f\left(e_{1}, a\right)$ and that the quality as an elite player in Stage 2 is given by $S_{2}=g\left(e_{1}, e_{2}\right)$. To save on notation, we omit $S_{1}$ and $S_{2}$ and use the quality functions $f($.$) and g($.$) directly. With the alternative notation, we would have S_{1}=f\left(e_{1}, a\right)$, which is strictly
} 
We will then assume that an elite player draws expected net utility $\delta \cdot v\left(g\left(e_{1}, e_{2}\right)\right)-C_{2}\left(e_{2}\right)$ from his elite quality $g$. The utility function $v(g(\cdot))$ as an elite is strictly increasing and strictly concave in quality $g$, i.e., $v_{g}^{\prime}>0, v_{g g}^{\prime \prime}<0$, with $v(0)=0$. Elite training effort is also associated with a cost $C_{2}\left(e_{2}\right)$, which is strictly increasing and strictly convex, i.e., $C_{2}^{\prime}\left(e_{2}\right)>0, C_{2}^{\prime \prime}\left(e_{2}\right)>0$, with $C_{2}(0)=0 .{ }^{19}$

The maximization program (1)-(3) can also be described by the following Lagrange function:

$$
\begin{aligned}
\mathcal{L}\left(e_{1}, e_{2}\right)= & \underbrace{\underbrace{u\left(f\left(e_{1}, a\right)\right)-C_{1}\left(e_{1}\right)}_{\text {Net utility as a youth player }}+\underbrace{\delta \cdot v\left(g\left(e_{1}, e_{2}\right)\right)-C_{2}\left(e_{2}\right)}_{\text {Expected net utility as an elite player }}}_{U\left(e_{1}, e_{2}\right)} \\
& -\underbrace{\lambda \cdot\left[F-f\left(e_{1}, a\right)\right]}_{\text {Entry constraint for elite football }}-\underbrace{\mu \cdot\left[\tilde{U}(a)-U\left(e_{1}, e_{2}\right)\right]}_{\text {Participation constraint }} .
\end{aligned}
$$

where, again, $u\left(f\left(e_{1}, a\right)\right)-C_{1}\left(e_{1}\right)$ is the net utility as an youth player in Stage 1, and $\delta \cdot v\left(g\left(e_{1}, e_{2}\right)\right)-C_{2}\left(e_{2}\right)$ is the expected net utility of a player who participates in the elite program in Stage 2. $\lambda$ is the Lagrange multiplier of the quality constraint associated with being admitted into the elite program and $\mu$ is the Lagrange multiplier of the participation constraint. In Section 5, we will solve this utility maximization problem by backward induction and derive each players equilibrium training effort.

\section{The equilibrium training effort}

In this section, we will determine how the selection system for elite training programs affects player effort in training and how this effort depends on the birthday of a player.

\subsection{Stage 2: Elite training}

In Stage 2, players decide their senior effort level. If a player fails to uphold a youth quality of at least $F$, then he is not admitted into elite training. Since participation in elite senior football can only be reached through elite training, a player outside the elite program has no incentive to invest in elite training. Hence, the player would choose $e_{2}=0$.

However, given that the player passes the youth quality threshold and is admitted into the elite program, such that $f\left(e_{1}, a\right)>F$, constraint (2) is not binding. Therefore, $\lambda=0$ in (4). Moreover, assuming that training for and playing elite football gives a higher utility than playing for fun, i.e., $U\left(e_{1}, e_{2}\right)>\tilde{U}(a)$, the participation constraint (3) is not binding, and we have $\mu=0$ in (4). In this case, the first-order condition for elite training $e_{2}$, given a fixed level of youth training $e_{1}$, is:

$$
\frac{\partial \mathcal{L}}{\partial e_{2}}=0 \longleftrightarrow \delta \cdot v_{g}^{\prime} \cdot g_{e_{2}}^{\prime}=C_{2}^{\prime}\left(e_{2}^{*}\right)
$$

increasing but strictly concave in youth training effort, i.e. $\partial S_{1} / \partial e_{1}=f_{e_{1}}^{\prime}>0, \partial^{2} S_{1} / \partial e_{1}^{2}=f_{e_{1} e_{1}}^{\prime \prime}<0$ with $f(0, a)=0$, $\partial S_{1} / \partial a=f_{a}^{\prime}\left(e_{1}, a\right)>0$. and $\partial^{2} S_{1} / \partial e_{1} \partial a=f_{e_{1} a}^{\prime \prime} \geq 0$. Then, defining elite skill in Stage 2 as $S_{2}=g\left(f\left(e_{1}, a^{\text {max }}\right), e_{2}\right)$ elite skills stem partly from youth player skills which are acquired in Stage $1, S_{1}=f\left(e_{1}, a\right)$, and partly from elite youth training efforts in Stage 2, where $\partial S_{2} / \partial e_{1}>0$. Note that we are then subsuming two distinct effects into the partial derivative of youth training on elite skill, i.e. $g_{e_{1}}^{\prime}=g_{S_{1}}^{\prime} \cdot f_{e_{1}}^{\prime}\left(e_{1}, a^{\max }\right)>0$, where elite skill is increasing in youth quality, $g_{S_{1}}^{\prime}>0$ and youth skill is increasing in youth training, $f_{e_{1}}^{\prime}>0$. Finally, we can assume that elite skill function $g\left(e_{1}, e_{2}\right)$ is strictly concave in youth training $\partial^{2} S_{2} / \partial e_{1}^{2}=g_{e_{1} e_{1}}^{\prime \prime}<0$.

${ }^{19}$ Without loss of generality, we may assume $C_{2}$ to be the same as the cost function for youth training, i.e., $C_{1}=C_{2}$. 
Thus, the marginal utility of effort $\delta \cdot v_{g}^{\prime} \cdot g_{e_{2}}^{\prime}$ depends on the degree of training efficiency $g_{e_{2}}^{\prime}$, how much the skill is valued $v_{g}^{\prime}$ and the probability of remaining fit $\delta$. The marginal utility of effort equals the marginal cost of effort $C^{\prime}\left(e_{2}^{*}\right)$, which can be interpreted as the cost of giving up alternative activities such as leisure, studies or other work.

How does an elite player's final skill $g\left(e_{1}, e_{2}\right)$ depend on the effort as a youth player $e_{1}$ ? Define the reduced-form utility function as $g\left(e_{1}\right)=g\left(e_{1}, e_{2}^{*}\left(e_{1}\right)\right)$. The marginal effect of youth effort $e_{1}$ is:

$$
\frac{d g\left(e_{1}, e_{2}^{*}\left(e_{1}\right)\right)}{d e_{1}}=g_{e_{1}}^{\prime}+g_{e_{2}}^{\prime} \frac{d e_{2}^{*}}{d e_{1}}
$$

where, by assumption, $g_{e_{1}}^{\prime}>0$, and $g_{e_{2}}^{\prime}>0$. The last term, $d e_{2}^{*} / d e_{1}$, measures the marginal effect of youth effort on elite effort $e_{2}$ and is given by:

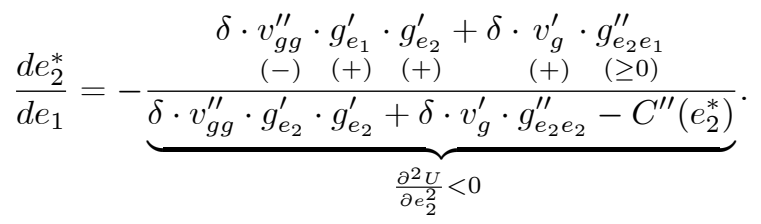

See Appendix 8.2.1 for a formal derivation of this result. Since the denominator $\partial^{2} U / \partial e_{2}^{2}$ is negative (see Lemma 2 in Appendix 8.2.1), the sign of (7) is determined by the sign of its numerator. Lemma 1 in Appendix 8.2.1 shows that the sign depends on the relationship between the degree of concavity, as measured by the coefficient of absolute risk aversion $-v_{g g}^{\prime \prime} / v_{g}^{\prime}$, and a measure of complementarity between youth and elite youth effort, given by $g_{e_{2} e_{1}}^{\prime \prime} / g_{e_{1}}^{\prime} g_{e_{2}}^{\prime}$.

If elite utility is sufficiently concave in quality (i.e., $-v_{g g}^{\prime \prime} / v_{g}^{\prime}>g_{e_{2} e_{1}}^{\prime \prime} / g_{e_{1}}^{\prime} g_{e_{2}}^{\prime}$ ), then more youth effort will lead to spending less effort as an elite, that is, $d e_{2}^{*} / d e_{1}<0$. In this case, youth effort is a substitute for elite effort. On the other hand, if youth and elite effort are sufficiently complementary activities (i.e., $\left.g_{e_{2} e_{1}}^{\prime \prime} / g_{e_{1}}^{\prime} g_{e_{2}}^{\prime}>-v_{g g}^{\prime \prime} / v_{g}^{\prime}\right)$, then more youth effort will lead to more effort as an elite, i.e., $d e_{2}^{*} / d e_{1}>0$. In such cases, expending a large amount of youth effort makes the player better able to take advantage of effort exerted as an elite player, in which case the two activities reinforce each other.

However, as the following result shows, elite quality $g$ will always increase in the amount of youth effort regardless of whether youth and elite effort are substitutes or complements.

Proposition 1 An elite senior player's final quality increases in his youth training effort,

$$
\frac{d g\left(e_{1}, e_{2}^{*}\left(e_{1}\right)\right)}{d e_{1}}>0
$$

Proof. See Appendix 8.2.1.

This result says that even if the player invests more in youth effort in the first period and expends less effort in the second period (i.e., $d e_{2}^{*} / d e_{1}<0$ ), he will always expend enough effort as a youth player that he never loses his initial advantage. Put differently, those who do not exert enough effort as youth players will never be able to recoup their lost effort. The mechanism behind this result is that even though a player with more accumulated human capital $e_{1}$ has a weaker incentive to invest in effort in the second period, because utility as an elite is concave $\left(v^{\prime \prime}<0\right)$, the marginal cost for the player with more accumulated human capital is still lower for the same skill level. Thus, the player with less human capital will never be able to catch 
up. A direct consequence of this result is that players who expend the most effort as youth players will eventually become superstars.

\subsection{Stage 1: Youth training}

As illustrated in Figure 4, a player's investment in youth effort depends on his choice of whether to try to participate in elite training or to play for fun. The next two sections look at how much youth effort is associated with each path.

\subsubsection{Playing for fun}

First, consider the case in which the player chooses to participate only on a youth team and abstains from trying to participate in the elite. In this case, the player does not expend any effort in Stage 2, i.e., $e_{2}=0$. Since the player abstains from Stage $2, v(0)=0$, the player simply maximizes his net youth utility, $u\left(f\left(e_{1}, a\right)\right)-C\left(e_{1}\right)$. With non-binding constraints $\lambda=\mu=0$ in (4), the first-order condition is:

$$
\frac{\partial \mathcal{L}}{\partial e_{1}}=0 \longleftrightarrow u_{f}^{\prime} \cdot f_{e_{1}}^{\prime}=C\left(\widetilde{e}_{1}(a)\right)
$$

The indirect utility from playing for fun for a player with age capital $a$ is $\widetilde{U}(a) \equiv u\left(f\left(\widetilde{e}_{1}(a), a\right)\right)-C\left(\widetilde{e}_{1}(a)\right)$. Figure 5 depicts the youth effort associated with playing for fun for a player with age capital $a_{A}$. It also shows the indirect utility for player A at point $\tilde{A}$.

\subsubsection{Aiming for the elite program}

Assume instead that the player finds it worthwhile to choose a sufficiently large amount of youth effort to obtain a place in the elite program, such that his youth quality is above the threshold $F$, i.e., $f\left(e_{1}, a\right)>F$. How much will the player invest in youth training? ${ }^{20}$

From (1) and (5), we define the reduced-form utility function as $U\left(e_{1}\right) \equiv U\left(e_{1}, e_{2}^{*}\left(e_{1}\right)\right)$. In this case, the constraints are non-binding in (4), $\lambda=\mu=0$, and the first-order condition for the youth effort level is given by:

$$
\frac{\partial \mathcal{L}}{\partial e_{1}}=0 \longleftrightarrow \underbrace{u_{f}^{\prime} \cdot f_{e_{1}}^{\prime}}_{u_{e_{1}}^{\prime}}+\delta \cdot \underbrace{v_{g}^{\prime} \cdot g_{e_{1}}^{\prime}}_{v_{e_{1}}^{\prime}}=C^{\prime}\left(e_{1}^{*}(a)\right) .
$$

The player internalizes that more youth effort increases the youth player utility given by $u_{e_{1}}^{\prime}=u_{f}^{\prime} \cdot f_{e_{1}}^{\prime}$. However, exerting a greater amount of youth effort produces a corresponding higher expected utility as an elite player, which is given by $\delta \cdot v_{g}^{\prime} \cdot g_{e_{1}}^{\prime}$. Figure 5(ii) depicts the first-order condition for youth effort for a player with age capital $a_{A}$ who chooses effort $e_{1}^{*}\left(a_{A}\right)$. The marginal utility of higher effort, $u_{e_{1}}^{\prime}+\delta \cdot v_{e_{1}}^{\prime}$ intersects with marginal effort $\operatorname{cost} C^{\prime}$ at point A. This choice is associated with a maximum utility at point A in Figure 5(i). ${ }^{21}$

Intuitively, when comparing the first-order conditions (8) and (9), it follows that participating in the elite program elicits more youth effort, i.e., $e_{1}^{*}(a)>\tilde{e}_{1}(a)$. Let $U(a) \equiv U\left(e_{1}^{*}(a)\right)$ be the indirect utility from the first-order conditions (5) and (9). For player A, we notice that participating in the elite program gives

\footnotetext{
${ }^{20}$ Derivations and additional comparative statics can be found in Appendix 8.2.2.

${ }^{21}$ The marginal utility locus $u_{e_{1}}^{\prime}+\delta \cdot v_{e_{1}}^{\prime}$ cuts off the margin effort cost locus $C^{\prime}$ from above by our assumption of a stable interior solution.
} 


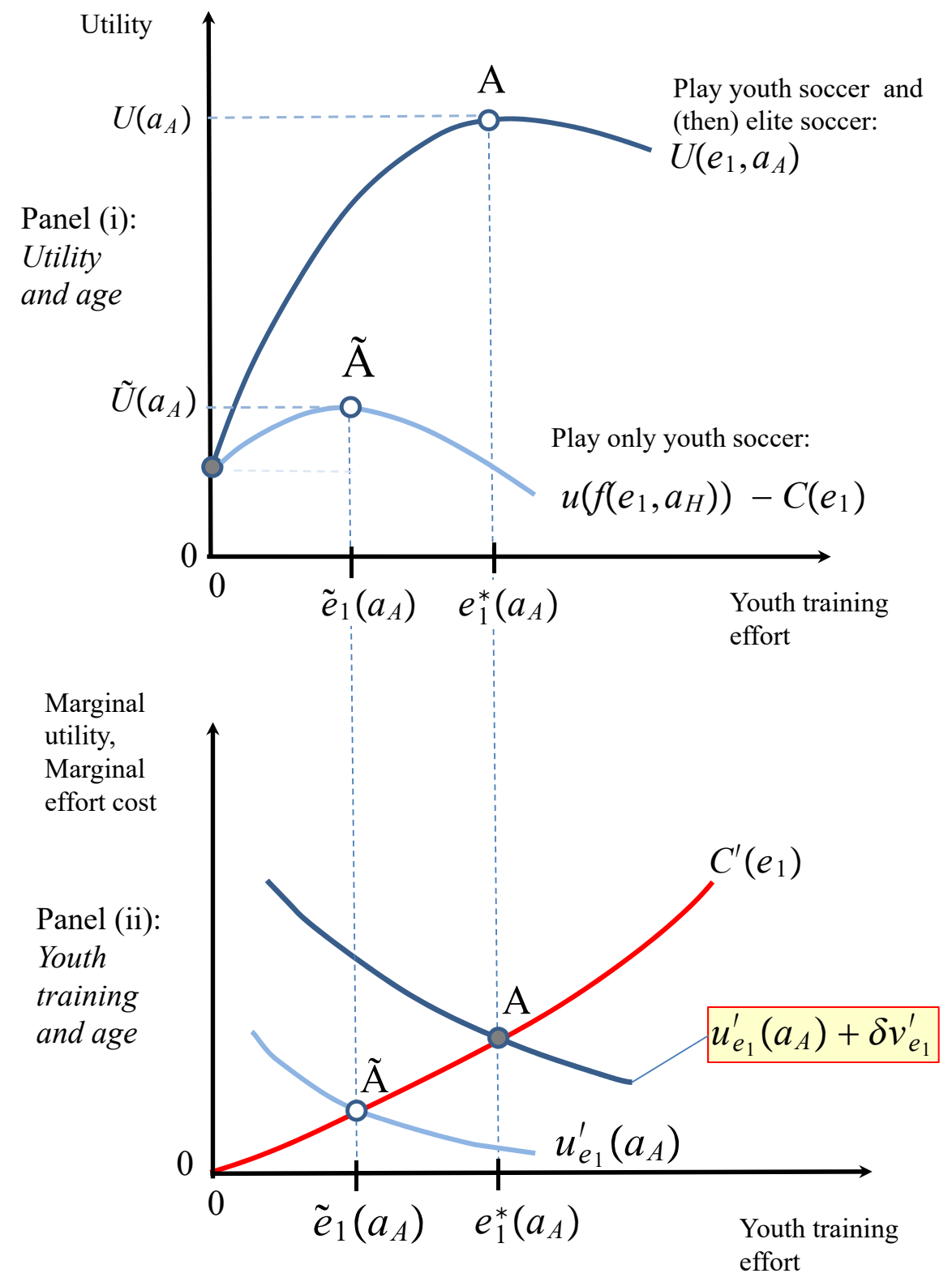

Figure 5: Illustrating the optimal effort in youth training in Stage 1 when future elite training in Stage 2 is internalized, $e_{1}^{*}\left(a_{A}\right)$, and the amount of youth training chosen when just playing for fun, $e_{1}^{*}\left(a_{A}\right)$, abstaining from elite training and in Stage 2. 
a much higher expected utility than playing for fun, which is illustrated by $U\left(a_{A}\right)>\tilde{U}\left(a_{A}\right)$. Hence, why should not all youth players aim for an elite career? As we will describe in the next section, this decision depends on the cost associated with the effort level $e_{1}$ in Stage 1 , which is directly related to the institutional setting (i.e., selection system) and age capital.

\subsection{The underdog incentive effect: the impact of age capital on youth training}

This section explores how youth training effort is related to age capital. Consider the following assumptions. ${ }^{22}$

\section{Assumption 1 (Concavity Beats COMplementarity) We assume:}

(a) The youth utility function is more concave than the degree of complementarity between youth effort and age capital, i.e.,

$$
\frac{f_{e_{1} a}^{\prime \prime}}{f_{a}^{\prime} f_{e_{1}}^{\prime}}<-\frac{u_{f f}^{\prime \prime}}{u_{f}^{\prime}} .
$$

(b) The elite utility function is more concave than the degree of complementarity between youth and elite efforts, i.e.,

$$
\frac{g_{e_{1} e_{2}}^{\prime \prime}}{g_{e_{1}}^{\prime} g_{e_{2}}^{\prime}}<-\frac{v_{g g}^{\prime \prime}}{v_{g}^{\prime}}
$$

We can then derive the following results.

Proposition 2 We have:

(i) Players born later in the year obtain less utility than players born early in the year, i.e.,

$$
\frac{d U}{d a}>0
$$

(ii) Suppose that Assumption 1(a) holds. Then, players who are born later in the year will spend more effort as youth players, i.e.,

$$
\frac{d e_{1}^{*}}{d a}<0
$$

(iii) Suppose Assumption 1(a)-(b) holds and define the reduced form youth quality for a player in the elite program as $f(a) \equiv f\left(e_{1}^{*}(a), a\right)>F$. Then players born earlier in the year have a higher youth quality, i.e.,

$$
\frac{d f}{d a}>0
$$

Proof. See Appendix 8.2.3.

We illustrate (i) and (ii) in Proposition 2 in Figure 6. Suppose that player A is born earlier in the year than player B, i.e., $a_{A}>a_{B}$. The lower age capital of player B leads to a lower indirect utility, i.e., $U\left(a_{A}\right)>U\left(a_{B}\right)$, which is shown by points A and B in Figure 6(ii), and illustrates Proposition 2(i). The lower utility of the younger player B is also associated with higher effort in youth training. We call this the underdog incentive effect, which is illustrated in Figure 6(ii) by the marginal utility of youth training shifting

\footnotetext{
${ }^{22}$ We analyse the effects of reversing Assumption 1 in Section 6.1.
} 


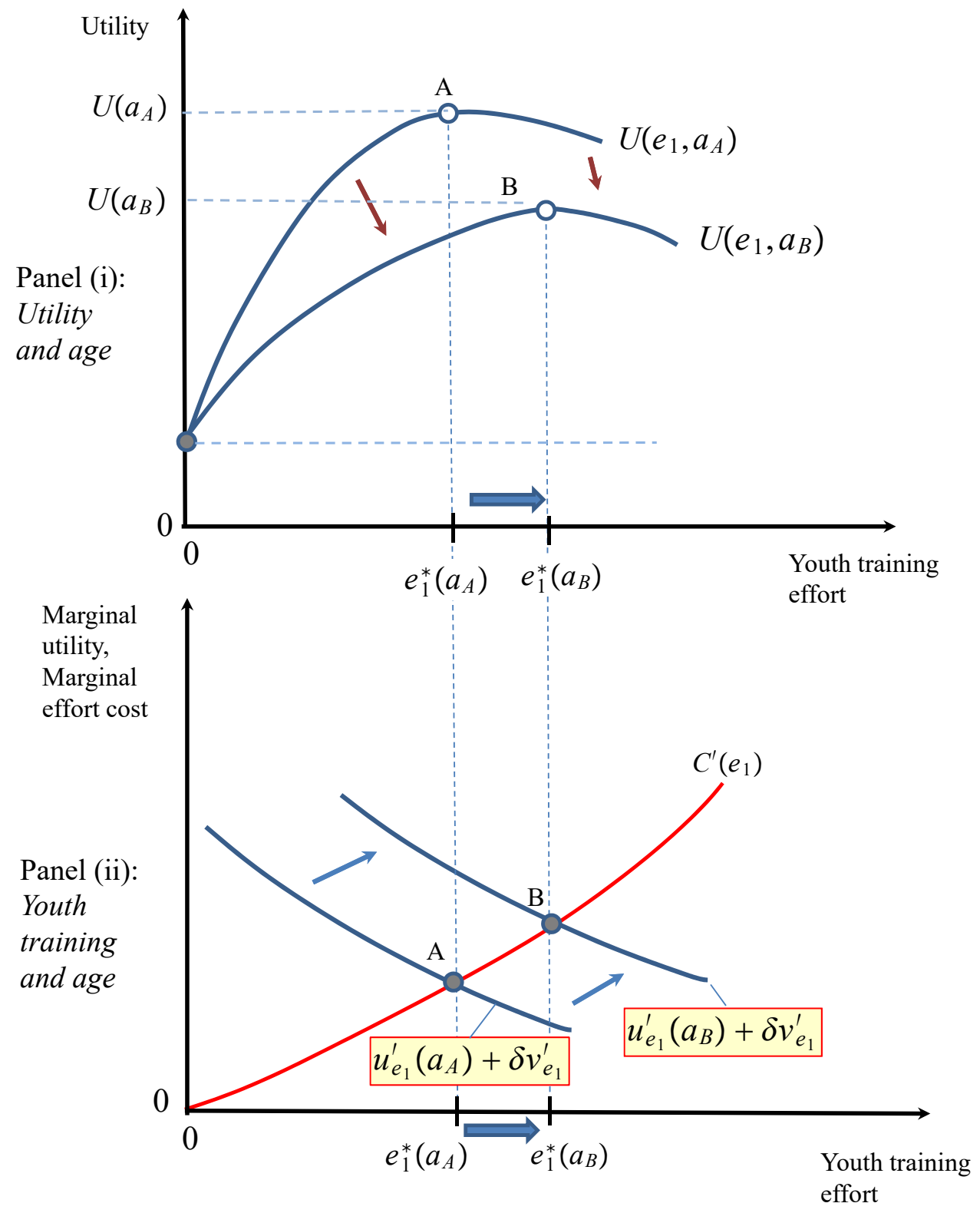

Figure 6: Illustrating the effects of age capital on youth effort, youth quality and utility. 
up from the locus $u_{e_{1}}^{\prime}\left(a_{A}\right)+\delta \cdot v_{e_{1}}^{\prime}$ to the locus $u_{e_{1}}^{\prime}\left(a_{B}\right)+\delta \cdot v_{e_{1}}^{\prime}$. The intuition is that the lower age capital $a_{B}<a_{A}$ induces a direct reduction in youth player quality $f$. This induces the player to expend more effort in order to compensate for the loss of quality. Consequently, the younger player B will expend more youth effort than the older player A, i.e., $e_{1}^{*}\left(a_{B}\right)>e_{1}^{*}\left(a_{A}\right)$, which illustrates Proposition 2(ii). However, it is also likely that increased effort in youth training cannot compensate for the loss of age capital, which implies the lower youth player quality of players who are born later in the year. This effect is formalized in Proposition 2(iii) and has important implications for how the selection into the elite program will proceed.

\subsection{The underdog selection effect}

In Figure 7(iii), we depict the critical combination of age capital (vertical axis) and youth effort (horizontal axis) needed to maintain the minimum youth quality needed to participate in the elite program in Stage 2. This occurs when the elite constraint (2) is binding, i.e., $f\left(e_{1}, a\right)=F$. The elite constraint is downward sloping, which implies that less age capital can only be offset by higher youth effort if the player wants to participate in the elite program.

Figure 7(iii) further shows all combinations of age capital and youth effort located to the right of the entry-constraint locus and marked in grey allow for participation in the elite program. The elite constraint is binding for player $\mathrm{B}$, who is born later in the year, i.e., $f\left(a_{B}\right)=f\left(e_{1}^{*}\left(a_{B}\right), a_{B}\right)=F$, but it is not binding for player $\mathrm{A}$, who is born earlier in the year, i.e., $f\left(a_{A}\right)=f\left(e_{1}^{*}\left(a_{A}\right), a_{A}\right)>F$.

Now, consider a third player, player $\mathrm{C}$, who is born even later than player B, i.e., $a_{C}<a_{B}$, and notice that the interior solution for youth effort from (9) is no longer valid for C. From Proposition 2(iii), the interior solution $e_{1}^{*}\left(a_{C}\right)$ would imply a level youth quality that is too low, in which case player $\mathrm{C}$ would be excluded from the elite program. Thus, to participate in the elite program, player $\mathrm{C}$ would have to adjust his youth effort. Figure 8(iii) shows that player C must pick a youth effort $\hat{e}_{1}\left(a_{C}\right)>e_{1}^{*}\left(a_{C}\right)$ to move from the interior solution $\mathrm{C}$ to the constrained solution $\hat{\mathrm{C}}$. In this case, the minimal quality constraint binds, i.e., $f\left(\hat{e}_{1}\left(a_{C}\right), a\right)=F$. Figure $8(\mathrm{i})$ then shows that player C's increased youth effort decreases his utility, i.e., $\hat{U}\left(a_{C}\right) \equiv U\left(\hat{e}\left(a_{C}\right), a_{C}\right)<U\left(a_{C}\right) \equiv U\left(e^{*}\left(a_{C}\right), a_{C}\right)$. We will refer to this constrained player as an underdog, since he cannot choose his optimal effort because he is forced to train harder in order to participate in elite training.

Finally, consider a player D born very late in the year. This player must exert even greater training effort to reach the youth quality necessary to participate in elite training. This is shown in Figure 7(ii) and (iii), where the interior solution in D and the constrained solution in $\hat{D}$ are now even further apart. Intuitively, the enormous strain placed on player D to try to participate in the elite program yields him with a much lower utility than that of any of the other players, A, B or C. In fact, Player D is indifferent between playing for fun and choosing low youth effort, $\tilde{e}_{1}\left(a_{D}\right)<\hat{e}_{1}\left(a_{D}\right)$, where $\hat{e}_{1}\left(a_{D}\right)$ is the effort necessary to reach the minimum quality required to participate in elite training, i.e., $f\left(\hat{e}_{1}\left(a_{D}\right), a\right)=F$, and where $\tilde{e}_{1}\left(a_{D}\right)$ is given from the first-order condition (8).

As shown in Figure 7(i), when the age capital of a player falls below $a_{D}$ (i.e., when the player is born very late in the year), the entry condition on participation in elite training becomes too demanding. He is then better off playing for fun and will eventually resign his ambition to reach the elite program. We refer to this distinct pattern - wherein youth players who are born late relentlessly increase their effort to try to reach the elite but eventually resign when exposed to a training load the is too demanding - as the underdog selection effect.

As a final remark on the quality as an elite, consider players A, C and D in Figure 8. Notice how 


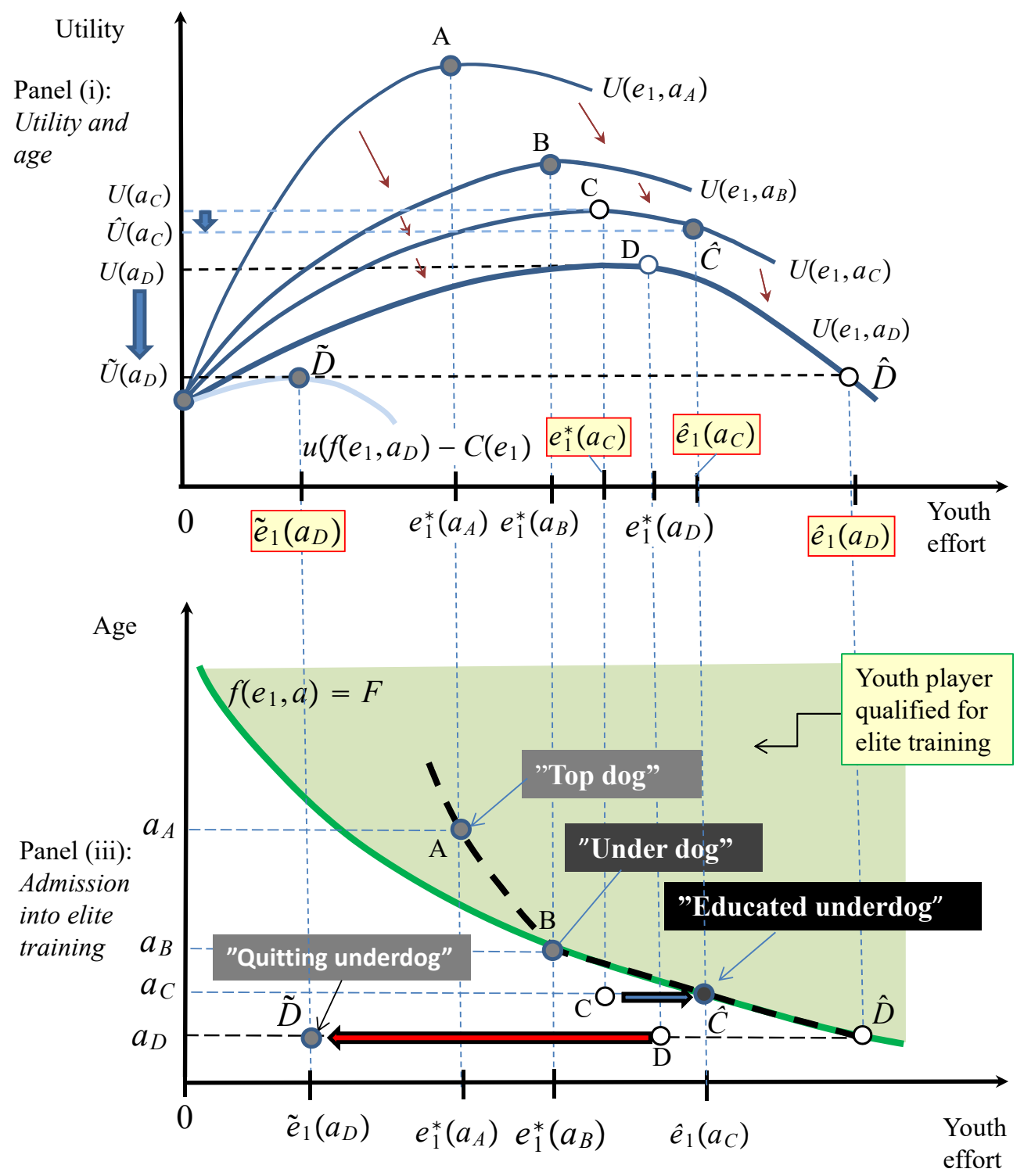

Figure 7: Illustrating the elite program constraint. 


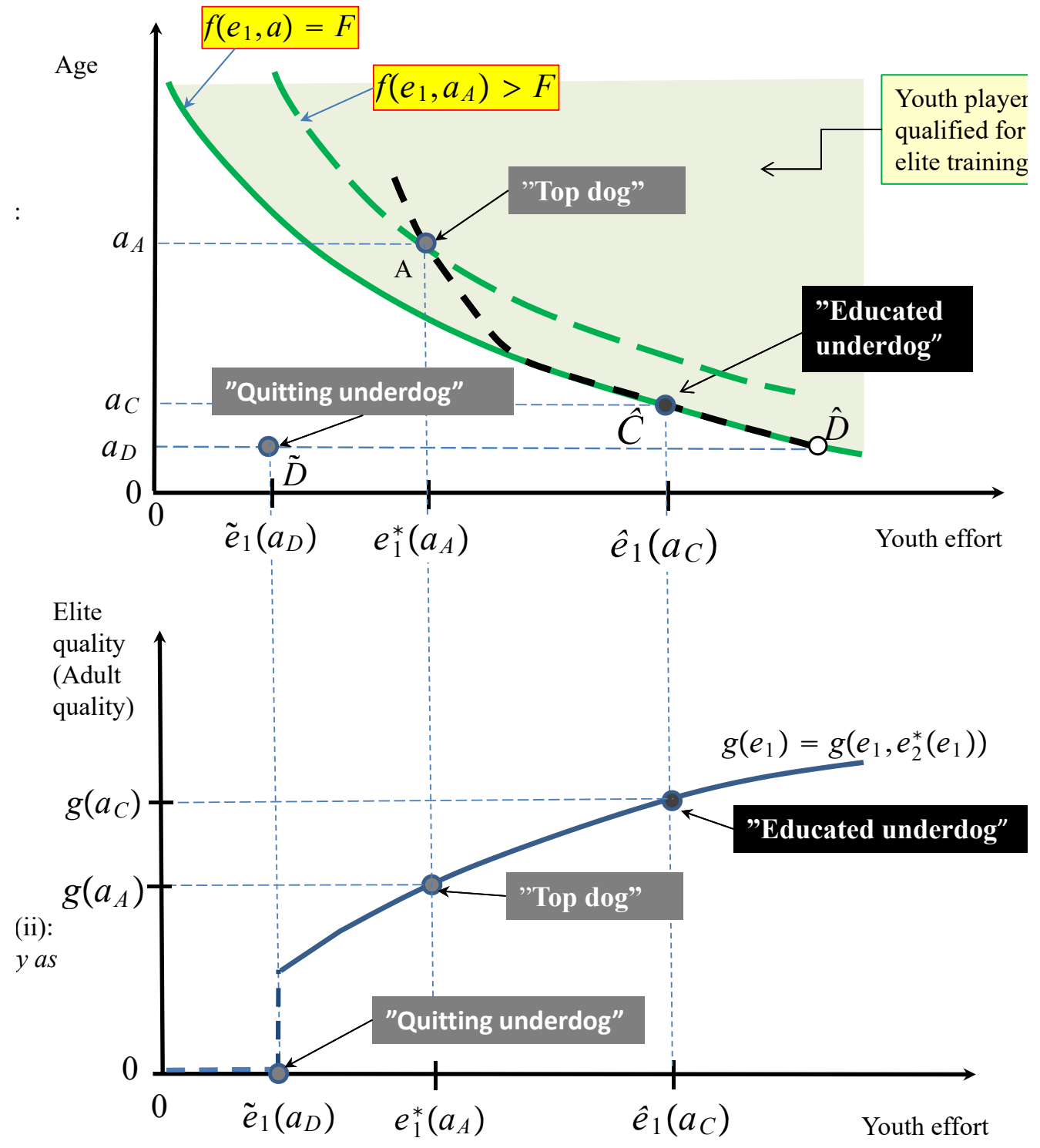

Figure 8: Illustrating the elite program constraint and the effects of youth effort on elite senior quality. 
player A, the "top-dog", has the most age capital and displays the highest youth quality. This is shown by the iso-quality curve running through point A located above the iso-quality curve $F$, where the latter reflects the combination of age capital and youth effort needed to participate in the elite program. First, notice that player $\mathrm{C}$ chooses a higher youth effort than player $\mathrm{A}$ in order to remain in the elite program, i.e., $e_{1}^{*}\left(a_{C}\right)>e_{1}^{*}\left(a_{A}\right)$. Second, notice that player D chooses a much lower effort than either player A or $\mathrm{C}$, i.e., $e_{1}^{*}\left(a_{D}\right)<e_{1}^{*}\left(a_{A}\right)<e_{1}^{*}\left(a_{B}\right)$. This reflects player D's choice to resign due to insufficient age capital to participate in the elite program.

From Proposition 7, we know that elite quality $g$ is determined by youth effort in Stage 1, i.e., $g\left(a_{C}\right)>$ $g\left(a_{B}\right)>g\left(a_{A}\right)>g\left(a_{D}\right)$. Thus, age capital $a$ does not have a direct effect on senior quality by the end of Stage 2. That is, age capital matters only through its impact on youth effort $e_{1}$ and elite effort $e_{2}$. As shown in Proposition 7, because youth effort is important to high elite quality, it follows that players born later in the year exhibit higher senior quality than players born earlier in the year. Accordingly, the lower age capital of players born later in the year gives them an incentive to expend more youth effort. This is shown in the lower panel of Figure 8, which depicts senior quality conditional on succeeding in the elite program to become an elite senior player.

Combining these results leads to the following conclusion. The player born later, player $\mathrm{C}$ - the educated underdog - will have lower youth quality than the player born earlier, player A (the top-dog ), i.e., $f\left(a_{C}\right)<$ $f\left(a_{A}\right)$. This is reversed when $\mathrm{A}$ and $\mathrm{C}$ both become elite senior players. In other words, if both $\mathrm{A}$ and $\mathrm{C}$ become elite senior players, then player $\mathrm{C}$ will be of higher quality, i.e., $g\left(a_{C}\right)>g\left(a_{A}\right)$. This can be explained by the fact that the disadvantage of a lower age capital translates into an advantage as an elite senior player. Our model ascribes this effect to the educated underdog who is forced to expend greater effort as a youth player. On the other hand, player $\mathrm{D}$, who is endowed with even less age capital than $\mathrm{C}$, is subjected to an excessively demanding youth effort level and, consequently, resigns. Hence, as he does not derive enough utility, player D refrains from becoming an elite senior player.

The following proposition summarizes the main results presented in this section.

Proposition 3 Suppose that Assumption 1 holds. Then:

(i) Players who are born later in the year and participate in the elite program (i.e., the educated underdogs) are of higher senior quality than those who are born earlier in the year and participate in the elite program (i.e., the top dogs). That is,

$$
\frac{\partial g\left(e_{1}, e_{2}\right)}{\partial a}<0 .
$$

(ii) Players who are born sufficiently late in the year refrain from participating in the elite program, and consequently, have the lowest senior quality (equal to zero).

Proof. See Appendix 8.2.4.

\subsection{Explaining the stylized facts}

In this section, we describe how our model explains the stylized facts documented in Section 3.

Stylized fact 1: Youth national team. Stylized fact 1 says that there is a strong RAE in elite youth football. Thus, players who are born earlier in the year are overrepresented on the youth national team. Part (iii) of Proposition 2 can explain this fact. Specifically, it shows that youth quality will be higher for 
players born earlier in the year because they have more age capital. Although players born later in the year will try to compensate for this deficit by expending more effort, it will not be sufficient to reach the quality level of the players who were born earlier, since the marginal cost of effort is convex in effort.

Stylized fact 2: The Guldbollen. Stylized fact 2 says that there is an inverse RAE among the very best players in Sweden (i.e., the winners of the Guldbollen award). Thus, players born late (but not too late) are overrepresented in among the winner of the Guldbollen. Part (i) of Proposition 3 can explain this fact. It shows that players born late in the year who participate in elite training, i.e., the educated underdogs, are of higher quality as senior players than those players born early in the year. The reason is that the educated underdog has a stronger incentive to increase his youth effort in order to participate in the elite program. This extra accumulation of human capital will persist into adulthood because players born early in the year have no incentive to expend more effort, since he can reach the elite program quality level without exerting extra effort and the marginal cost of effort is convex.

Stylized fact 3: Non-participation. Stylized fact 3 says that players who are born very late in the year are underrepresented among the winners of the Guldbollen award. Part (ii) of Proposition 3 explain this fact. The underdog selection effect says that players born very late in the year increase their youth effort in order to participate in the elite program. However, the marginal cost of effort needed to participate in the elite program is too large, which implies that these players eventually abstain from pursuing an elite career.

\section{Extensions}

In this section, we discuss some modifications and extensions of our model.

\subsection{When will players that are born early in the year become superstars?}

It is often argued that players born earlier in the year receive much more attention from coaches and teachers and obtain more practise and playing time. If this effect is strong, this would imply that Assumption 1 would not hold but the reversed as stated in Assumption 2.

Assumption 2 (COMplementarity Beats COnCAVity) Assume that the youth utility function is less concave than the measure of complementarity between youth effort and age capital, i.e.,

$$
\frac{f_{e_{1} a}^{\prime \prime}}{f_{a}^{\prime} f_{e_{1}}^{\prime}}>-\frac{u_{f f}^{\prime \prime}}{u_{f}^{\prime}}
$$

Assumption 2 holds if the utility of playing youth football $u(\cdot)$ is not too concave and if youth training and age capital $f_{e_{1} a}^{\prime \prime}$ are sufficiently complementary activities.

Figure 9 describes how the main variables of interest in the model depend on the player's birthday under Assumption 1 (referred to as "concavity beats complementarity"). In contrast, Figure 10 illustrates the model under Assumption 2 (referred to as "complementarity beats concavity").

Figure 9 and 10 has age capital on the horizontal axis while the vertical axes depict our main variable of interest: (a) youth effort $e_{1}(a)$, (b) youth player quality $f(a)$, (c) indirect utility $U(a)$ and, finally, (d) senior player quality $g(a)$ - all expressed as reduced-form functions of age capital $(a)$. 


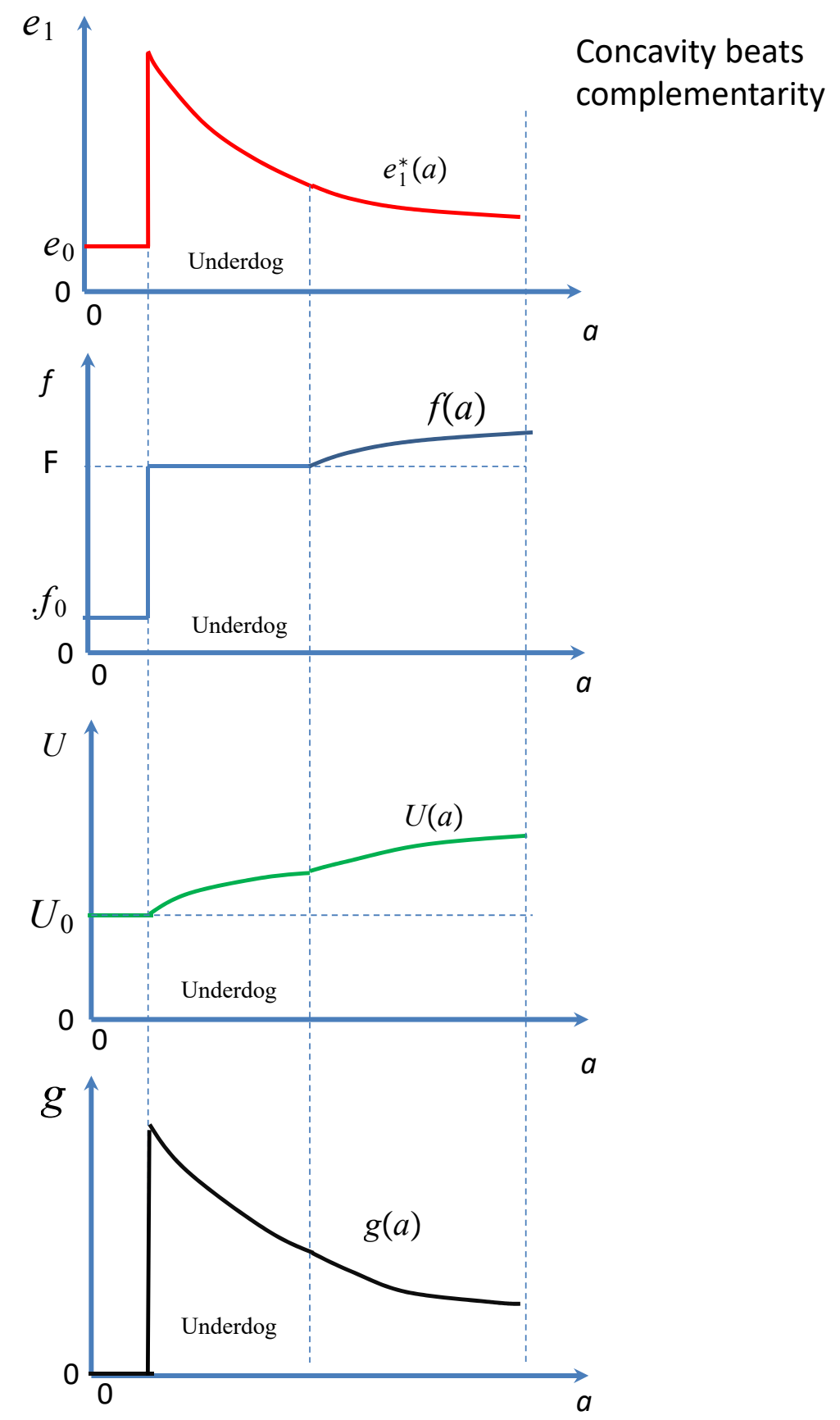

Figure 9: Illustrating the model under "concavity beats complementarity". 


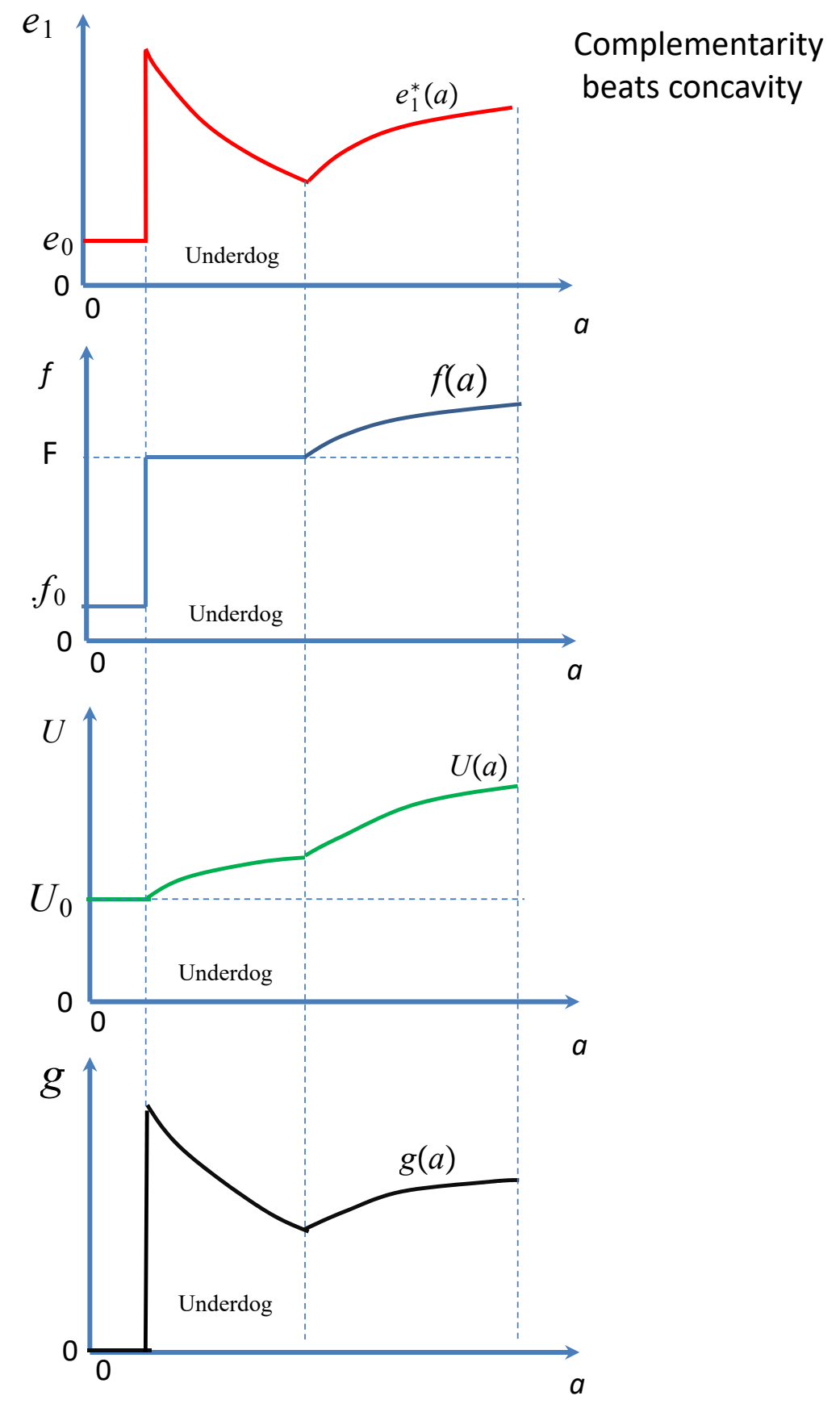

Figure 10: Illustrating the model under "complementarity beats concavity". 
Let us start by summarizing our main case, i.e. when Assumption 1 (i.e., "concavity beats complementarity") holds. Inspecting panel (a) in Figure 9 we note that children with very low age capital, $a<a_{0}$, will not exert a high level of effort as young players, i.e. $e_{1}^{*}(a)=e_{0}$. The reason that they will not be able to make it into elite training programs. However, at some level of age capital, it is worthwhile going for the elite education, and the effort curve then jumps upward. However, then, at higher levels of age capital, the child need to put less effort into training to make it into the program, and the effort curve becomes downward sloping. Figure (b) maps this effort $e_{1}^{*}(a)$ and age capital $a$ onto youth skill $f(a)$. We find that skill $f(a)$ is increasing in age capital $a$ but that we have a region where $f(a)$ is independent of age capital $a$, i.e. the region where the elite program threshold is binding. Figure (c) maps this effort level $e_{1}^{*}(a)$, age capital $a$ and cost of effort $C_{1}\left(e_{1}^{*}(a)\right)$ onto an indirect utility $U(a)$. We find that the indirect utility $U(a)$ is increasing in age capital $a$, since an older child can get more out of his football practise and thus need to work less hard. Finally, inspecting panel (d), we note that children with very low age capital will not reach high skill levels as adults $g^{*}(a)$, since they exerted little effort as young players. However, at some level of age capital, it is worthwhile going for the elite education, and the adult skill curve $g^{*}(a)$ then jumps upward. However, then, at even higher age capital levels, the child needs to exert less effort in training to make it into the program, and the adult skill curve $g^{*}(a)$ then becomes downward sloping.

Let us now turn to the opposite case, i.e. Assumption 2 (i.e., "complementarity beats concavity") holds. Inspecting panel (a) in Figure 10, we now find that the effort curve $e_{1}^{*}(a)$ behaves the same for low levels of age capital $a$. However, at sufficiently high level of $a$, the effort curve $e_{1}^{*}(a)$ reaches a minimum and start increasing. The reason for this is that the complementarity starts to beat concavity, and thus, the individual with more age capital is able to get much more out of his training. Thus, he puts more effort into training than an individual with less age capital. Inspecting panels (b) and (c) gives qualitatively similar effects as under Assumption 1. However, interestingly, panel (d) reveals a different picture. Again, children with very low age capital will not reach high skill levels as adults $g^{*}(a)$, since they exerted little effort as young players. Moreover, at some level of age capital, it is worthwhile going for the elite education, and the adult

skill curve $g^{*}(a)$ then jumps upward.. Again, at higher age capital, the child needs to put less effort into training to make it into the program, and the adult skill curve $g^{*}(a)$ becomes downward sloping. Then, complementarity kicks in, and the individual with higher age capital $a$ will train harder. Thus, the adult skill curve $g^{*}(a)$ will start increasing, making a difference to the case under Assumption 1.

Summing up Figures 9 and 10, we find that the educated underdog effect is present under both assumptions. However, we also see that players born early in the year (with high $a$ ) might exert more effort as young player under Assumption 2 when the complementarity between youth training and age capital is high. This, in turn, implies that they might eventually outperform players born late in the year to ultimately become superstars.

\subsection{When does age capital not matter?}

Let us now turn to the issue of when a birthday will not affect skill as an adult. We have the following result.

COROLlary 1 An elite player's senior quality will not be affected by his youth training effort if $e_{1}$ and $e_{2}$ are perfect substitutes, i.e., $g_{e_{1}}^{\prime}=g_{e_{2}}^{\prime}$ and $g_{e_{1} e_{1}}^{\prime}=g_{e_{2} e_{2}}$, and the cost of effort is linear in effort, that is, if the marginal cost of training is constant, $C_{1}^{\prime \prime}=C_{2}^{\prime \prime}=0$

Thus, if the ability to train and training techniques are approximately stable over time and the cost of training is rather constant, then increasing effort as a youth player will not matter. In this case, we 
should not expect large differences in players' human capital accumulation, and inherent talent should be the decisive characteristic that explains any differences in elite senior quality.

\subsection{Different and multiple cut-off days: the case of France and Germany}

We have illustrated our theoretical model using detailed data over Swedish elite football. The cut-off to participate in club teams is January 1 in Sweden. But other countries have different cut-offs dates. In France and Germany, for example, these dates occur on September 1 and August 1, respectively. This raises the question whether the underdog effect also is present in countries with different cut-offs dates? Since the cut-off for participating in junior national teams is always January 1 there are two cut-off dates for countries with a domestic cut-off different from January 1. Thus, in this case, our model would predict that there are two different sources of relative age effects: one where players born in August and September are the oldest players and the other where the players that are born in January are the oldest. Consequently, the birthday distribution should have two distinct peaks: one about 7-11 months after the club cut-off (which corresponds to April-July for France and March-June for Germany).

As in Sweden, a prize for the best male football player has been award in France and Germany since 1959 and 1960, respectively. Figure 11 contains the kernel density plots of the birthday distribution of such winners in France (green line) and Germany (red line). ${ }^{23}$

As our theory predicts, we find bimodal distributions for France and Germany suggesting that the educated underdog effects is also present in countries with different club cut-offs. Notice that there is a second peak in the distributions in July-October which suggests that also the cut-off date for the national team January 1 is in play. These results suggest that multiple cut-offs can create more educated underdogs and make the distribution of superstars more aligned with the national population birthday distribution.

\subsection{Too little youth training? The paternalistic view}

It has been debated whether a youth player who is left to decide her own training effort will choose a level that is too low. Instead of investing in training, the child might spend too much time on leisure activities or spend too little time on school activities. Analysing this issue in detail is beyond the scope of this paper, but we will make some observation that we believe are noteworthy.

To this end, let us assume that the activity we study is the activity that should be maximized, but the child might discount the future too much. Thus, the paternalistic view would be that the child discounts the future too much, i.e., $\delta^{p}>\delta^{o}$, where $\delta^{p}$ is the paternalistic discount factor, and $\delta^{o}$ is the child's own discount factor.

From Eq. (9) and the implicit function theorem, we have:

$$
\frac{d e_{1}^{*}}{d \delta}=-\frac{v_{g}^{\prime} \cdot g_{e_{1}}^{\prime}}{u_{f}^{\prime \prime} \cdot f_{e_{1}}^{\prime} \cdot f_{e_{1}}^{\prime}+u_{f}^{\prime} \cdot f_{e_{1}}^{\prime \prime}+\delta\left(v_{g}^{\prime \prime} \cdot g_{e_{1}}^{\prime} \cdot g_{e_{1}}^{\prime}+v_{g}^{\prime} \cdot g_{e_{1}}^{\prime \prime}\right)+\delta\left(v_{g}^{\prime \prime} \cdot g_{e_{1}}^{\prime} \cdot g_{e_{2}}^{\prime} \frac{d e_{2}^{*}}{d e_{1}}+v_{g}^{\prime} \cdot g_{e_{1} e_{2}}^{\prime \prime} \frac{d e_{2}^{*}}{d e_{1}}\right)-C^{\prime \prime}}>0 .
$$

This result says that youth effort will increase as the discount factor decreases ( $\delta$ increases). It then follows directly that in equilibrium, unconstrained children who are early born will exert too little effort on training compared to the paternalistic optimal level $e_{1}^{* p}>e_{1}^{* o}$. Moreover, it might then follow that children who are

\footnotetext{
${ }^{23}$ The UK, Italy and Spain have also best player awards. However, to our knowledge these awards are more informal than in Sweden, France and Germany. Moreover, in these countries there are too few observations to make any meaningful analysis.
} 


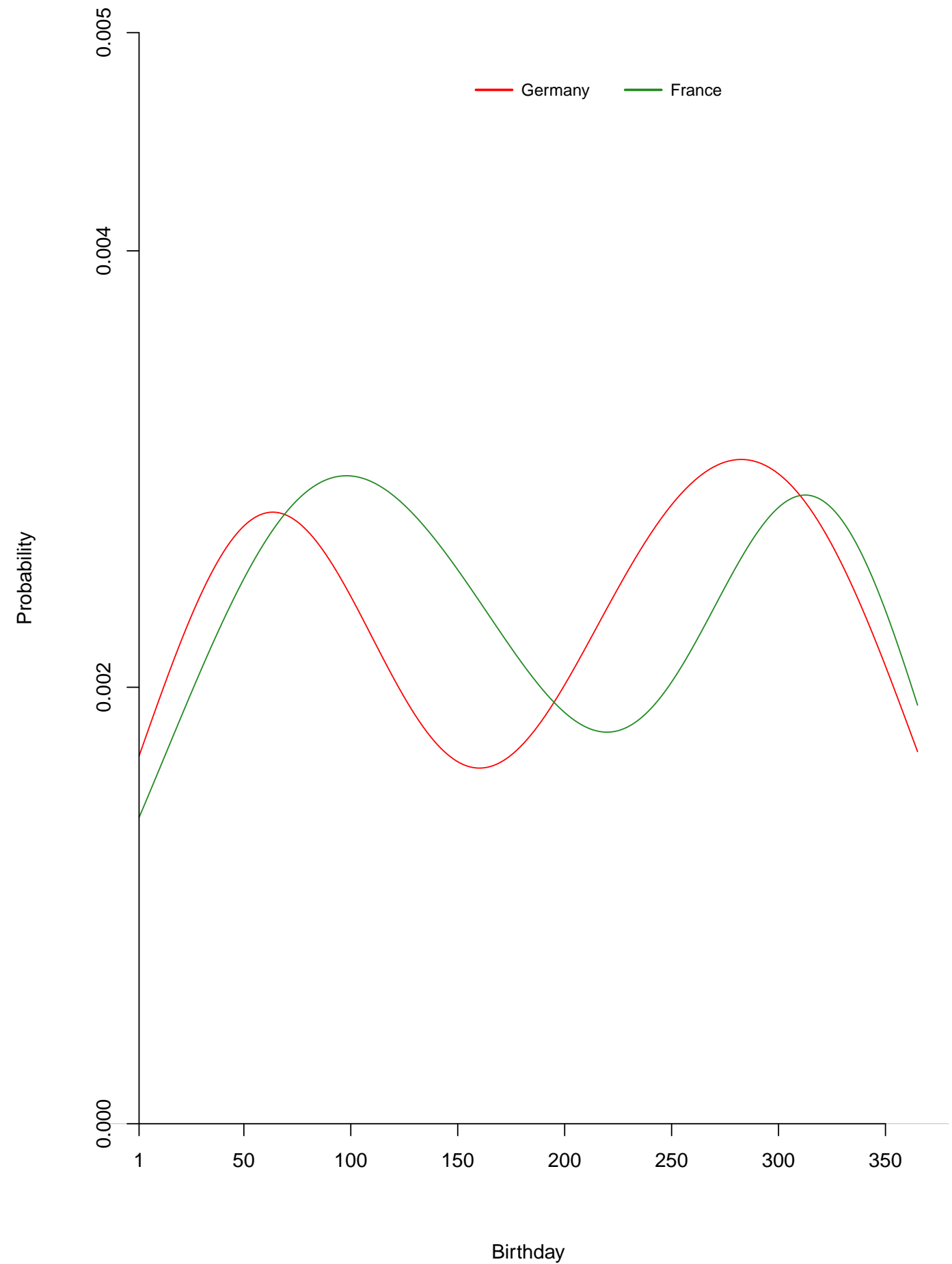

Figure 11: Kernel density plots of the birthdays of winners of the best player awards in France (green) and Germany (red). Notice that the cut-off dates have been adjusted in the plots. Hence, day 1 corresponds to September 1 for France and August 1 for Germany. 
pushed above the unconstrained effort level in period 1 might reach a higher total utility when evaluated under the paternalistic discount factor $U\left(a_{C}, \delta^{p}\right)>U\left(a_{A}, \delta^{p}\right)$. Thus, we can state the following result:

COROLLARY 2 If youth players have an excessively low discount factor compared to the optimal adult-based discount factor over their expected lifetime, then the educated underdog might not only be the superstar but also the individual with the highest expected life utility.

\section{Conclusions}

In this paper, we have taken a step towards a systematic investigation of how motivational, technological and institutional factors affect children's skill development. In a model where (i) all children have the same innate talent, (ii) individuals born earlier in the year have a temporary advantage in age capital, and (iii) there is selection into an elite education program, we show that an individual's day of birth affects her skill level as adult.

Under plausible assumptions, in particular, with sufficient concavity of utility and complementarity between age capital and human capital investment that is not too strong, individuals born later in the year that make it into elite programs (educated underdogs) will ultimately become the superstars. The reason is that these individuals will put in more effort in training as young players in order to be admitted into a future elite training program with their older competitors (underdogs are forced away from their interior solution to a corner solution with excessive training effort). This higher effort level will create a competitive advantage as adults for those born late that individuals born earlier will not find it worthwhile to match.

We have also presented data on (probably) the most competitive activity for children in the world, football (soccer). Consistent with the educated underdog effect, we find an inverted relation between the player's birthday and the likelihood of receiving the Ballon d'Or (awarded to the best football player in the world). Using detailed data on the performance of elite football players in Sweden, we find strong support for the predictions of the model.

In our model, talent plays no role. What would happen if we allowed for talent asymmetries? First, the mechanisms identified in our model should still be in play unless talent is extremely unevenly distributed. The educated underdog will still be more likely to ultimately become a superstar, since he or she will be more motivated to increase effort to obtain elite education. Second, we would probably see interesting interaction effects among talent, motivation and complementarity. For instance, Ericsson and Pool (2016) reports evidence that some talent advantages have features similar to those of the relative age effect i.e., a future expert is the one with high - but not too high - talent. The reason is that individuals who are too talented do not work sufficiently hard as young students and are therefore outcompeted by more motivated individuals. Interestingly, Bilalić et al. (2007) examine a group of 57 children playing chess. When dividing the group into an amateur group and an elite group, they found that children in the elite group, on average, had higher IQs. However, within the elite group, the correlation was reversed: children with lower IQs had better chess performance. This unexpected result is explained by a negative correlation between IQ and practice within the elite subsample, which is consistent with the idea of the educated underdog proposed in this paper. Extending our model to better understand how talent, motivation, complementarity and institutions interact to determine skill formation seems an interesting avenue for future research. ${ }^{24}$

\footnotetext{
${ }^{24}$ Vestberg et al. (2012), using a partial correlation test, found a significant correlation between the result from an executive test and the numbers of goals and assists the players scored two seasons later.
} 
We have also focused on the selective aspect of the educational system in our model. This has been motivated by the fact that this captures a fundamental (measurable) aspect of the football educational system in Sweden. However, there are, of course, other important elements of the educational system from which we have abstracted. An interesting aspect would be to compare different types of educational systems: Systems based on absolute performance could be compared to those based on relative performance; Systems based on more deliberate practise elements could compared to more traditional ones. More generally, extending the model to derive optimal educational systems under resource and informational constraints seems an interesting avenue for future research.

\section{Appendix}

\subsection{Appendix A: Regression results}

\begin{tabular}{ll}
\hline \hline Variable & Definition \\
\hline Birthday & Player's day of birth in the calender year \\
Goalkeeper & 1 if the player's main position was as goalkeeper, and 0 otherwise \\
Midfielder & 1 if the player's main position was as midfielder, and 0 otherwise \\
Attacker & 1 if the player's main position was as attacker, and 0 otherwise \\
International & 1 if he played in an international (i.e., non-Swedish) league, \\
& and 0 otherwise \\
Year of debut & Age when player did his first senior national team match \\
Team performance & The difference between the number of goals scored and goals against \\
& by the national team during the player's time in the team \\
"Stora grabbar" & 1 if the player has received the "Stora grabbar" award, and 0 otherwise \\
"Guldbollen" & 1 if the player has received the "Guldbollen" award, and 0 otherwise \\
\hline \hline
\end{tabular}

Notes: There are in total 650 observations on each variable (i.e., for each senior national team player).

Table A1: Data for each senior national team player 


\begin{tabular}{lcc}
\hline \hline & \multicolumn{2}{c}{ Dependent variable } \\
\cline { 2 - 3 } Independent variables & "Stora grabbar" & "Guldbollen" \\
\hline & & \\
ln (Birthday) & $0.037^{* * *}$ & 0.008 \\
Goalkeeper & 0.027 & 0.034 \\
Midfielder & -0.003 & -0.012 \\
Attacker & -0.017 & -0.005 \\
Played abroad & $0.057^{*}$ & 0.020 \\
ln (Year of debut) & $-0.394^{* * *}$ & -0.020 \\
Team performance & $0.017^{* * *}$ & $0.003^{* * *}$ \\
Mean & & 0.080 \\
\# Observations & 0.317 & 650 \\
\hline \hline
\end{tabular}

Notes: ${ }^{* * *}$ and ${ }^{*}$ denotes significance on the $1 \%$ and $10 \%$ nominal significance levels, respectively. See Table A1 for a definition of the variables.

Table A2: Marginal effects in the Probit model 


\begin{tabular}{lccc}
\hline \hline & \multicolumn{3}{c}{ Dependent variable: Birthday } \\
\cline { 2 - 4 } Independent variables & Quantile 0.5 & Quantile 0.90 & Quantile 0.95 \\
\hline \multirow{3}{*}{ "Guldbollen" } & $52.363^{* *}$ & $-18.568^{* *}$ & $-12.837^{* *}$ \\
Goalkeeper & -3.514 & -0.554 & 6.903 \\
Midfielder & -0.016 & -0.532 & 2.347 \\
Attacker & 1.294 & 8.446 & 0.044 \\
Played abroad & 11.362 & 3.568 & $11.453^{* *}$ \\
ln (Year of debut) & $122.622^{* *}$ & $93.110^{* * *}$ & 20.779 \\
Team performance & 0.448 & 0.386 & -0.120 \\
& & & \\
\# Observations & 650 & 650 & 650 \\
\hline \hline
\end{tabular}

Notes: ${ }^{* * *}$ and ${ }^{* *}$ denotes significance on the $1 \%$ and $5 \%$ nominal significance levels, respectively. See Table A1 for a definition of the variables.

Table A3: Quantile regression results

\subsection{Appendix B: Proofs}

\subsubsection{Proofs and derivations for Section 5.1}

The first-order conditions in Eq. (5) can be written as:

$$
\frac{\partial U\left(e_{1}, e_{2}^{*}\left(e_{1}\right)\right)}{\partial e_{2}}=\delta \cdot v_{g}^{\prime}\left(g\left(e_{1}, e_{2}\right)\right) \cdot g_{e_{2}}^{\prime}\left(e_{1}, e_{2}\right)-C_{2}^{\prime}\left(e_{2}\right)
$$

The corresponding second-order conditions are

$$
\begin{aligned}
& \frac{\partial^{2} U\left(e_{1}, e_{2}^{*}\left(e_{1}\right)\right)}{\partial e_{2}^{2}}=\delta \cdot \underset{(-)}{v_{g g}^{\prime \prime}} \cdot \underset{(+)}{g_{e_{2}}^{\prime}} \cdot \underset{(+)}{g_{e_{2}}^{\prime}}+\delta \cdot \underset{(+)}{v_{g}^{\prime}} \cdot \underset{(-)}{g_{e_{2} e_{2}}^{\prime \prime}}-\underset{(+)}{C_{2}^{\prime \prime}\left(e_{2}^{*}\right)<0,} \\
& \frac{\partial^{2} U\left(e_{1}, e_{2}^{*}\left(e_{1}\right)\right)}{\partial e_{2} \partial e_{1}}=\delta \cdot \underset{(-)}{v_{g g}^{\prime \prime}} \cdot \underset{(+)}{g_{e_{1}}^{\prime}} \cdot \underset{(+)}{g_{e_{2}}^{\prime}}+\delta \cdot \underset{(+)}{v_{g}^{\prime}} \cdot \underset{(\geq 0)}{g_{e_{2} e_{1}}^{\prime \prime}} \text {. }
\end{aligned}
$$

Given the first order condition from the Lagrange function in Eq. (5), the assumption of an interior solution implies

$$
\begin{aligned}
\frac{\partial U\left(e_{1}, e_{2}^{*}\left(e_{1}\right)\right)}{\partial e_{2}} & =\delta \cdot v_{g}^{\prime}\left(g\left(e_{1}, e_{2}\right)\right) \cdot g_{e_{2}}^{\prime}\left(e_{1}, e_{2}\right)-C_{2}^{\prime}\left(e_{2}\right) \\
& =0 .
\end{aligned}
$$

Thus, in optimum, the following relation must hold:

$$
\frac{\partial^{2} U}{\partial e_{2} \partial e_{1}}+\frac{\partial^{2} U}{\partial e_{2}^{2}} \cdot \frac{d e_{2}^{*}}{d e_{1}}=0 \longleftrightarrow \frac{d e_{2}^{*}}{d e_{1}}=-\frac{\frac{\partial^{2} U}{\partial e_{2} \partial e_{1}}}{\frac{\partial^{2} U}{\partial e_{2}^{2}}} .
$$


Inserting (11) and (12), we obtain Eq. (7):

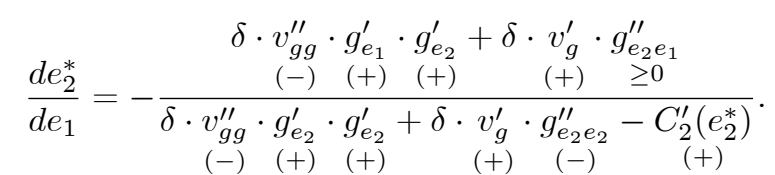

The following lemma characterizes the sign of (14).

Lemma 1 We have the following cases:

(i) More youth training reduces the amount of elite training if the utility as an elite player is sufficiently concave in relation to the degree of complementarity between youth and elite training, i.e.,

$$
\frac{d e_{2}^{*}}{d e_{1}}<0 \quad \text { if } \quad \frac{g_{e_{2} e_{1}}^{\prime \prime}}{g_{e_{2}}^{\prime} g_{e_{1}}^{\prime}}<-\frac{v_{g g}^{\prime \prime}}{v_{g}^{\prime}}
$$

(ii) The amount of elite training is independent of the amount of youth training if the degree of complementarity between youth and elite training is equal to the degree of concavity of utility as an elite player, i.e.,

$$
\frac{d e_{2}^{*}}{d e_{1}}=0 \quad \text { if } \quad \frac{g_{e_{2} e_{1}}^{\prime \prime}}{g_{e_{2}}^{\prime} g_{e_{1}}^{\prime}}=-\frac{v_{g g}^{\prime \prime}}{v_{g}^{\prime}}
$$

(iii) More youth training increases the amount of elite training if the utility as an elite player is less concave than the degree of complementarity between youth and elite training, i.e.,

$$
\frac{d e_{2}^{*}}{d e_{1}}>0 \quad \text { if } \quad \frac{g_{e_{2} e_{1}}^{\prime \prime}}{g_{e_{2}}^{\prime} g_{e_{1}}^{\prime}}>-\frac{v_{g g}^{\prime \prime}}{v_{g}^{\prime}}
$$

Proof of Lemma 1. We only show (i) (cases (ii) and (iii) follow analogously). Since the denominator of (14) is negative, the sign of $d e_{2}^{*} / d e_{1}$ is determined by the sign of the numerator in (14). Thus, $d e_{2}^{*} / d e_{1}<0$ trivially follows since:

$$
\delta \cdot v_{g g}^{\prime \prime} \cdot g_{e_{1}}^{\prime} \cdot g_{e_{2}}^{\prime}+\delta \cdot v_{g}^{\prime} \cdot g_{e_{2} e_{1}}^{\prime \prime}<0 \longleftrightarrow \frac{g_{e_{2} e_{1}}^{\prime \prime}}{g_{e_{2}}^{\prime} g_{e_{1}}^{\prime}}<-\frac{v_{g g}^{\prime \prime}}{v_{g}^{\prime}}
$$

We now turn to the proof of Proposition 1.

Proof of Proposition 1. Define the reduced-form elite quality $g\left(e_{1}\right)=g\left(e_{1}, e_{2}^{*}\left(e_{1}\right)\right)$. Eq. (6) states that:

$$
\frac{d g\left(e_{1}, e_{2}^{*}\left(e_{1}\right)\right)}{d e_{1}}=g_{e_{1}}^{\prime}+g_{e_{2}}^{\prime} \frac{d e_{2}^{*}}{d e_{1}}
$$

Clearly, this expression is positive whenever $d e_{2}^{*} / d e_{1} \geq 0$ since $g_{e_{1}}^{\prime}>0$ and $g_{e_{2}}^{\prime}>0$ holds by assumption. Thus, we need only to consider the case $d e_{2}^{*} / d e_{1}<0$. To show this, suppose, by contradiction, that $d e_{2}^{*} / d e_{1}<$ 
0 but $d g\left(e_{1}, e_{2}^{*}\left(e_{1}\right)\right) / d e_{1} \leq 0$. We have:

$$
\begin{aligned}
\frac{d g\left(e_{1}, e_{2}^{*}\left(e_{1}\right)\right)}{d e_{1}} & =g_{e_{1}}^{\prime}+g_{e_{2}}^{\prime} \frac{d e_{2}^{*}}{d e_{1}} \\
& =g_{e_{2}}^{\prime} \cdot\left(\frac{g_{e_{1}}^{\prime}}{g_{e_{2}}^{\prime}}+\frac{d e_{2}^{*}}{d e_{1}}\right) \\
& =g_{e_{2}}^{\prime} \cdot\left(\frac{g_{e_{1}}^{\prime}}{g_{e_{2}}^{\prime}}-\frac{\delta \cdot v_{g g}^{\prime \prime} \cdot g_{e_{1}}^{\prime} \cdot g_{e_{2}}^{\prime}+\delta \cdot v_{g}^{\prime} \cdot g_{e_{2} e_{1}}^{\prime \prime}}{\delta \cdot v_{g g}^{\prime \prime} \cdot g_{e_{2}}^{\prime} \cdot g_{e_{2}}^{\prime}+\delta \cdot v_{g}^{\prime} \cdot g_{e_{2} e_{2}}^{\prime \prime}-C_{2}^{\prime}\left(e_{2}\right)}\right) \\
& \leq 0,
\end{aligned}
$$

where the third row follows from (14) and the inequality in the fourth row holds by assumption. Because $g_{e_{2}}^{\prime}>0$, this is equivalent to that:

$$
\frac{g_{e_{1}}^{\prime}}{g_{e_{2}}^{\prime}} \leq \frac{\delta \cdot v_{g g}^{\prime \prime} \cdot g_{e_{1}}^{\prime} \cdot g_{e_{2}}^{\prime}+\delta \cdot v_{g}^{\prime} \cdot g_{e_{2} e_{1}}^{\prime \prime}}{\delta \cdot v_{g g}^{\prime \prime} \cdot g_{e_{2}}^{\prime} \cdot g_{e_{2}}^{\prime}+\delta \cdot v_{g}^{\prime} \cdot g_{e_{2} e_{2}}^{\prime \prime}-C_{2}^{\prime}\left(e_{2}\right)}
$$

Thus, since $g_{e_{1}}^{\prime}>0$ and $g_{e_{2}}^{\prime}>0$ we have

$$
\begin{aligned}
\frac{g_{e_{1}}^{\prime}}{g_{e_{2}}^{\prime}} & \leq \frac{\delta \cdot v_{g g}^{\prime \prime} \cdot g_{e_{1}}^{\prime} \cdot g_{e_{2}}^{\prime}+\delta \cdot v_{g}^{\prime} \cdot g_{e_{2} e_{1}}^{\prime \prime}}{\delta \cdot v_{g g}^{\prime \prime} \cdot g_{e_{2}}^{\prime} \cdot g_{e_{2}}^{\prime}+\delta \cdot v_{g}^{\prime} \cdot g_{e_{2} e_{2}}^{\prime \prime}-C_{2}^{\prime}\left(e_{2}\right)} \longleftrightarrow \\
1 & \leq \frac{g_{e_{2}}^{\prime}}{g_{e_{1}}^{\prime}}\left(\frac{\delta \cdot v_{g g}^{\prime \prime} \cdot g_{e_{1}}^{\prime} \cdot g_{e_{2}}^{\prime}+\delta \cdot v_{g}^{\prime} \cdot g_{e_{2} e_{1}}^{\prime \prime}}{\delta \cdot v_{g g}^{\prime \prime} \cdot g_{e_{2}}^{\prime} \cdot g_{e_{2}}^{\prime}+\delta \cdot v_{g}^{\prime} \cdot g_{e_{2} e_{2}}^{\prime \prime}-C_{2}^{\prime}\left(e_{2}\right)}\right) \\
& =\frac{g_{e_{2}}^{\prime} \cdot \delta \cdot v_{g g}^{\prime \prime} \cdot g_{e_{2}}^{\prime}+\frac{g_{e_{2}}^{\prime}}{g_{e_{1}}^{\prime}} \cdot \delta \cdot v_{g}^{\prime} \cdot g_{e_{2} e_{1}}^{\prime \prime}}{\delta \cdot v_{g g}^{\prime \prime} \cdot g_{e_{2}}^{\prime} \cdot g_{e_{2}}^{\prime}+\delta \cdot v_{g}^{\prime} \cdot g_{e_{2} e_{2}}^{\prime \prime}-C_{2}^{\prime}\left(e_{2}\right)}
\end{aligned}
$$

Since the denominator is negative this yields

$$
\begin{aligned}
\delta \cdot v_{g g}^{\prime \prime} \cdot g_{e_{2}}^{\prime} \cdot g_{e_{2}}^{\prime}+\delta \cdot v_{g}^{\prime} \cdot g_{e_{2} e_{2}}^{\prime \prime}-C_{2}^{\prime}\left(e_{2}\right) & \geq g_{e_{2}}^{\prime} \cdot \delta \cdot v_{g g}^{\prime \prime} \cdot g_{e_{2}}^{\prime}+\frac{g_{e_{2}}^{\prime}}{g_{e_{1}}^{\prime}} \cdot \delta \cdot v_{g}^{\prime} \cdot g_{e_{2} e_{1}}^{\prime \prime} \longleftrightarrow \\
g_{e_{2} e_{2}}^{\prime \prime} & \geq \frac{g_{e_{2}}^{\prime}}{g_{e_{1}}^{\prime}} \cdot g_{e_{2} e_{1}}^{\prime \prime}+C_{2}^{\prime}\left(e_{2}\right),
\end{aligned}
$$

where the second row follows because $\delta \cdot v_{g g}^{\prime \prime} \cdot g_{e_{2}}^{\prime} \cdot g_{e_{2}}^{\prime}$ cancels out and $\delta \cdot v_{g}^{\prime}>0$. But this would imply $g_{e_{2} e_{2}}^{\prime \prime} \geq 0$ since all terms on the right-hand side are non-negative, which yields the wanted contradiction. Thus, de $e_{2}^{*} / d e_{1}<0$ implies $d g\left(e_{1}, e_{2}^{*}\left(e_{1}\right)\right) / d e_{1}>0$.

\subsubsection{Derivations and comparative statics for Section 5.2.2}

The reduced-form utility function for a player who passes the elite constraint is:

$$
\begin{aligned}
U\left(e_{1}\right) & \equiv U\left(e_{1}, e_{2}^{*}\left(e_{1}\right)\right) \\
& =u\left(f\left(e_{1}, a\right)\right)-C_{1}\left(e_{1}\right)+\delta \cdot v\left(g\left(e_{1}, e_{2}^{*}\left(e_{1}\right)\right)\right)-C_{2}\left(e_{2}^{*}\left(e_{1}\right)\right)
\end{aligned}
$$


The first order condition is:

$$
\begin{aligned}
\frac{d U\left(e_{1}\right)}{d e_{1}} & =\frac{\partial U\left(e_{1}, e_{2}^{*}\left(e_{1}\right)\right)}{\partial e_{1}}+\frac{\partial U\left(e_{1}, e_{2}^{*}\left(e_{1}\right)\right)}{\partial e_{2}} \cdot \frac{d e_{2}^{*}}{d e_{1}} \\
& =\frac{\partial U\left(e_{1}, e_{2}^{*}\left(e_{1}\right)\right)}{\partial e_{1}} \\
& =0
\end{aligned}
$$

where the second row follows because $\partial U\left(e_{1}, e_{2}^{*}\left(e_{1}\right)\right) / \partial e_{2}=0$ by (13). Thus, from (16) the first order condition becomes (i.e., Eq. (9)):

$$
\begin{aligned}
\frac{d U\left(e_{1}\right)}{d e_{1}} & =\frac{\partial U\left(e_{1}, e_{2}^{*}\left(e_{1}\right)\right)}{\partial e_{1}} \\
& =u_{f}^{\prime} \cdot f_{e_{1}}^{\prime}+\delta \cdot v_{g}^{\prime} \cdot g_{e_{1}}^{\prime}-C_{1}^{\prime} \\
& =0 .
\end{aligned}
$$

The second order condition is:

$$
\begin{aligned}
& \frac{\partial^{2} U}{\partial e_{1}^{2}}=u_{f f}^{\prime \prime} \cdot f_{e_{1}}^{\prime} \cdot f_{e_{1}}^{\prime}+u_{f}^{\prime} \cdot f_{e_{1} e_{1}}^{\prime \prime}+\delta \cdot v_{g g}^{\prime \prime} \cdot g_{e_{1}}^{\prime} \cdot g_{e_{1}}^{\prime}+\delta \cdot v_{g}^{\prime} \cdot g_{e_{1} e_{1}}^{\prime \prime} \\
& +\delta \cdot v_{g g}^{\prime \prime} \cdot g_{e_{2}}^{\prime} \cdot \frac{d e_{2}^{*}}{d e_{1}} \cdot g_{e_{1}}^{\prime}+\delta \cdot v_{g}^{\prime} \cdot g_{e_{1} e_{2}}^{\prime \prime} \cdot \frac{d e_{2}^{*}}{d e_{1}}-C_{1}^{\prime \prime}
\end{aligned}
$$

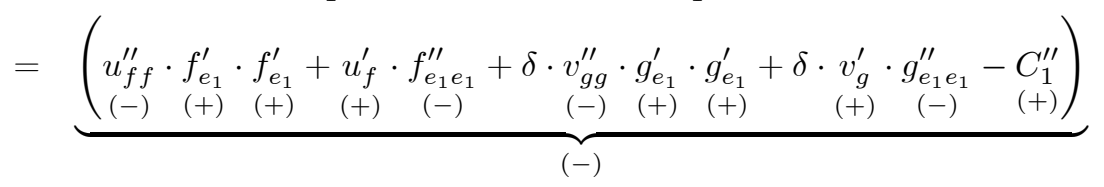

$$
\begin{aligned}
& \underbrace{\delta \cdot\left(v_{g g}^{\prime \prime} \cdot g_{e_{2}}^{\prime} \cdot g_{e_{1}}^{\prime}+v_{g}^{\prime} \cdot g_{e_{1} e_{2}}^{\prime \prime}\right) \cdot \frac{d e_{2}^{*}}{d e_{1}}}_{(\geq 0)} \\
& <0 \text {. }
\end{aligned}
$$

Lemma 2 We have $\partial^{2} U / \partial e_{1}^{2}<0$.

Proof of Lemma 2. Since the function $U$ is the sum of strictly concave functions (in $e_{1}$ and $e_{2}$ ), it is itself strictly concave (in $e_{1}$ and $e_{2}$ ). As such, the Hessian function of $U$ is negative definite. Thus, since $\partial^{2} U / \partial e_{1} \partial e_{2}=\partial^{2} U / \partial e_{2} \partial e_{1}$ by Young's theorem and $\partial^{2} U / \partial e_{2}^{2}<0$ by Eq. (11), we have:

$$
\frac{\partial^{2} U}{\partial e_{1}^{2}} \cdot \frac{\partial^{2} U}{\partial e_{2}^{2}}-\frac{\partial^{2} U}{\partial e_{1} \partial e_{2}} \cdot \frac{\partial^{2} U}{\partial e_{2} \partial e_{1}}>0 \rightarrow \frac{\partial^{2} U}{\partial e_{1}^{2}}<\frac{\left(\frac{\partial^{2} U}{\partial e_{1} \partial e_{2}}\right)^{2}}{\frac{\partial^{2} U}{\partial e_{2}^{2}}}<0
$$

which completes the proof. 


\subsubsection{Proofs and derivations for Section 5.3}

For convenience, we begin from the first order condition (18). The second order partial derivative with respect to age capital $a$ is given by:

$$
\frac{\partial^{2} U}{\partial e_{1} \partial a}=\frac{\partial^{2} u\left(f\left(e_{1}, a\right)\right)}{\partial f_{(-)}^{2}} \cdot \frac{\partial f\left(e_{1}, a\right)}{\partial a} \underset{(+)}{\partial a} \cdot \frac{\partial f\left(e_{1}, a\right)}{\partial e_{1}}+\frac{\partial u\left(f\left(e_{1}, a\right)\right)}{\partial f} \underset{(+)}{(+)} \cdot \frac{\partial^{2} f\left(e_{1}, a\right)}{\underset{(\geq 0)}{\partial a}} .
$$

Define the implicit function $e_{1}^{*}(a)$ and the corresponding reduced-form utility function as:

$$
U\left(e_{1}^{*}(a), a\right)=U\left(e_{1}^{*}(a), e_{2}^{*}\left(e_{1}^{*}(a), a\right)\right) .
$$

The envelope theorem implies that:

$$
\frac{\partial U\left(e_{1}^{*}(a), a\right)}{\partial e_{1}}=0 .
$$

Thus, in optimum, the partial derivative with respect to age capital must satisfy:

$$
\frac{\partial^{2} U\left(e_{1}^{*}(a), a\right)}{\partial e_{1}^{2}} \cdot \frac{d e_{1}^{*}}{d a}+\frac{\partial^{2} U\left(e_{1}^{*}(a), a\right)}{\partial e_{1} \partial a}=0 \longleftrightarrow \frac{d e_{1}^{*}}{d a}=-\frac{\frac{\partial^{2} U\left(e_{1}^{*}(a), a\right)}{\partial e_{1} \partial a}}{\frac{\partial^{2} U\left(e_{1}^{*}(a), a\right)}{\partial e_{1}^{2}}} .
$$

Plugging (19) and (20) into this expression yields:

$$
\frac{d e_{1}^{*}}{d a}=-\frac{\left(u_{f f}^{\prime \prime} \cdot f_{a}^{\prime} \cdot f_{e_{1}}^{\prime}+u_{f}^{\prime} \cdot f_{e_{1} a}^{\prime \prime}\right)}{\frac{\partial^{2} U\left(e_{1}^{*}(a), a\right)}{\partial e_{1}^{2}}}
$$

where $\partial^{2} U\left(e_{1}^{*}(a), a\right) / \partial e_{1}^{2}$ is given by (19).

We can now prove Proposition 2.

Proof of Proposition 2. Consider the optimization problem in Eq. (1). The utility of player who participates in elite training is described by the following indirect utility:

$$
\begin{aligned}
U(a) & =U\left(e_{1}^{*}(a), e_{2}^{*}\left(e_{1}^{*}(a)\right)\right) \\
& =u\left(f\left(e_{1}^{*}(a), a\right)\right)+\delta \cdot v\left(g\left(e_{1}^{*}(a), e_{2}^{*}\left(e_{1}^{*}(a)\right)\right)-C_{1}\left(e_{1}^{*}(a)\right)-C_{2}\left(e_{2}^{*}\left(e_{1}^{*}(a)\right)\right)\right.
\end{aligned}
$$


Thus,

$$
\begin{aligned}
& \frac{d U}{d a}=\frac{\partial u}{\partial f} \cdot \frac{\partial f}{\partial e_{1}} \cdot \frac{\partial e_{1}}{\partial a}+\frac{\partial u}{\partial f} \cdot \frac{\partial f}{\partial a}+\delta \cdot \frac{\partial v}{\partial g} \cdot \frac{\partial g}{\partial e_{1}} \cdot \frac{\partial e_{1}}{\partial a} \\
& +\delta \cdot \frac{\partial v}{\partial g} \cdot \frac{\partial g}{\partial e_{2}} \cdot \frac{\partial e_{2}}{\partial e_{1}} \cdot \frac{\partial e_{1}}{\partial a}-\frac{\partial C_{1}}{\partial e_{1}} \cdot \frac{\partial e_{1}}{\partial a}-\frac{\partial C_{2}}{\partial e_{2}} \cdot \frac{\partial e_{2}}{\partial e_{1}} \cdot \frac{\partial e_{1}}{\partial a} \\
& =\frac{\partial u}{\partial f} \cdot \frac{\partial f}{\partial e_{1}} \cdot \frac{\partial e_{1}}{\partial a}+\delta \cdot \frac{\partial v}{\partial g} \cdot \frac{\partial g}{\partial e_{1}} \cdot \frac{\partial e_{1}}{\partial a}-\frac{\partial C_{1}}{\partial e_{1}} \cdot \frac{\partial e_{1}}{\partial a} \\
& +\delta \cdot \frac{\partial v}{\partial g} \cdot \frac{\partial g}{\partial e_{2}} \cdot \frac{\partial e_{2}}{\partial e_{1}} \cdot \frac{\partial e_{1}}{\partial a}-\frac{\partial C_{2}}{\partial e_{2}} \cdot \frac{\partial e_{2}}{\partial e_{1}} \cdot \frac{\partial e_{1}}{\partial a}+\frac{\partial u}{\partial f} \cdot \frac{\partial f}{\partial a} \\
& =\left(\frac{\partial u}{\partial f} \cdot \frac{\partial f}{\partial e_{1}}+\delta \cdot \frac{\partial v}{\partial g} \cdot \frac{\partial g}{\partial e_{1}}-\frac{\partial C_{1}}{\partial e_{1}}\right) \cdot \frac{\partial e_{1}}{\partial a} \\
& +\left(\delta \cdot \frac{\partial v}{\partial g} \cdot \frac{\partial g}{\partial e_{2}}-\frac{\partial C_{2}}{\partial e_{2}}\right) \cdot \frac{\partial e_{2}}{\partial e_{1}} \cdot \frac{\partial e_{1}}{\partial a}+\frac{\partial u}{\partial f} \cdot \frac{\partial f}{\partial a} \\
& =\underbrace{\left(\frac{\partial u}{\partial f} \cdot \frac{\partial f}{\partial e_{1}}+\delta \cdot \frac{\partial v}{\partial g} \cdot \frac{\partial g}{\partial e_{1}}-\frac{\partial C_{1}}{\partial e_{1}}\right)}_{=\frac{d U}{\partial e_{1}}=0 \text { from Eq. (17) }} \cdot \frac{\partial e_{1}}{\partial a} \\
& +\underbrace{\left(\delta \cdot \frac{\partial v}{\partial g} \cdot \frac{\partial g}{\partial e_{2}}-\frac{\partial C_{2}}{\partial e_{2}}\right)}_{=\frac{d U}{\partial e_{2}}=0 \text { from Eq. }} \cdot \frac{\partial e_{2}}{\partial e_{1}} \cdot \frac{\partial e_{1}}{\partial a}+\frac{\partial u}{\partial f} \cdot \frac{\partial f}{\partial a} \\
& =\frac{\partial u}{\partial f} \cdot \frac{\partial f}{\partial a} \\
& >0 \text {, }
\end{aligned}
$$

which proves $(i)$.

To prove (ii), consider Eq. (21). Under the assumption that the second order condition is negative, i.e., $\partial^{2} U\left(e_{1}^{*}(a), a\right) / \partial e_{1}^{2}<0$, the sign of $d e_{1}^{*} / d a$ is determined by the sign of the numerator $u_{f f}^{\prime \prime} \cdot f_{a}^{\prime} \cdot f_{e_{1}}^{\prime}+u_{f}^{\prime} \cdot f_{e_{1} a}^{\prime \prime}$. Clearly, since $-\partial^{2} U\left(e_{1}^{*}(a), a\right) / \partial e_{1}^{2}>0$ we have de $e_{1}^{*} / d a<0$ if $u_{f f}^{\prime \prime} \cdot f_{a}^{\prime} \cdot f_{e_{1}}^{\prime}+u_{f}^{\prime} \cdot f_{e_{1} a}^{\prime \prime}<0$. The proof then follows by noticing that Assumption 1 holds if and only if $u_{f f}^{\prime \prime} \cdot f_{a}^{\prime} \cdot f_{e_{1}}^{\prime}+u_{f}^{\prime} \cdot f_{e_{1} a}^{\prime \prime}<0$.

To prove (iii), define the reduced form youth quality for a player training to become an elite as:

$$
f(a)=f\left(e_{1}^{*}(a), a\right)
$$

Thus,

$$
\frac{d f(a)}{d a}=\frac{\partial f\left(e_{1}^{*}(a), a\right)}{\partial e_{1}^{*}} \cdot \frac{\partial e_{1}^{*}(a)}{\partial a}+\frac{\partial f\left(e_{1}^{*}(a), a\right)}{\partial a} .
$$

To show that $\partial e_{1}^{*}(a) / \partial a<0$ implies $d f(a) / d a>0$, suppose, by contradiction, that $\partial e_{1}^{*}(a) / \partial a<0$ but df $(a) / d a \leq 0$. We have:

$$
\begin{aligned}
\frac{d f(a)}{d a} & =\frac{\partial f\left(e_{1}^{*}(a), a\right)}{\partial e_{1}^{*}} \cdot \frac{\partial e_{1}^{*}(a)}{\partial a}+\frac{\partial f\left(e_{1}^{*}(a), a\right)}{\partial a} \\
& =f_{a}^{\prime}+f_{e_{1}}^{\prime} \cdot \frac{d e_{1}^{*}}{d a} \\
& =f_{e_{1}}^{\prime} \cdot\left(\frac{f_{a}^{\prime}}{f_{e_{1}}^{\prime}}+\frac{d e_{1}^{*}}{d a}\right) \\
& \leq 0
\end{aligned}
$$


where the inequality in the fourth row holds by assumption. Because $f_{e_{1}}^{\prime}>0$ by assumption, this is equivalent to that:

$$
\begin{aligned}
\frac{f_{a}^{\prime}}{f_{e_{1}}^{\prime}} & \leq-\frac{d e_{1}^{*}}{d a} \\
& =\frac{\left(u_{f f}^{\prime \prime} \cdot f_{a}^{\prime} \cdot f_{e_{1}}^{\prime}+u_{f}^{\prime} \cdot f_{e_{1} a}^{\prime \prime}\right)}{\frac{\partial^{2} U\left(e_{1}^{*}(a), a\right)}{\partial e_{1}^{2}}},
\end{aligned}
$$

where the second row follows from Eq. (21). Thus, since $f_{a}^{\prime}>0$ and $f_{e_{1}}^{\prime}>0$ we have

$$
\begin{aligned}
\frac{f_{a}^{\prime}}{f_{e_{1}}^{\prime}} & \leq \frac{\left(u_{f f}^{\prime \prime} \cdot f_{a}^{\prime} \cdot f_{e_{1}}^{\prime}+u_{f}^{\prime} \cdot f_{e_{1} a}^{\prime \prime}\right)}{\frac{\partial^{2} U\left(e_{1}^{*}(a), a\right)}{\partial e_{1}^{2}}} \longleftrightarrow \\
1 & \leq \frac{f_{e_{1}}^{\prime}}{f_{a}^{\prime}} \frac{\left(u_{f f}^{\prime \prime} \cdot f_{a}^{\prime} \cdot f_{e_{1}}^{\prime}+u_{f}^{\prime} \cdot f_{e_{1} a}^{\prime \prime}\right)}{\frac{\partial^{2} U\left(e_{1}^{*}(a), a\right)}{\partial e_{1}^{2}}} \\
& =\frac{\left(u_{f f}^{\prime \prime} \cdot\left(f_{e_{1}}^{\prime}\right)^{2}+\frac{f_{e_{1}}^{\prime}}{f_{a}^{\prime}} \cdot u_{f}^{\prime} \cdot f_{e_{1} a}^{\prime \prime}\right)}{\frac{\partial^{2} U\left(e_{1}^{*}(a), a\right)}{\partial e_{1}^{2}}} .
\end{aligned}
$$

Since the denominator is negative this yields

$$
\frac{\partial^{2} U\left(e_{1}^{*}(a), a\right)}{\partial e_{1}^{2}} \geq u_{f f}^{\prime \prime} \cdot\left(f_{e_{1}}^{\prime}\right)^{2}+\frac{f_{e_{1}}^{\prime}}{f_{a}^{\prime}} \cdot u_{f}^{\prime} \cdot f_{e_{1} a}^{\prime \prime}
$$

Substituting $\partial^{2} U\left(e_{1}^{*}(a), a\right) / \partial e_{1}^{2}$ from (19) yields:

$$
\begin{aligned}
& u_{f f}^{\prime \prime} \cdot\left(f_{e_{1}}^{\prime}\right)^{2}+u_{f}^{\prime} \cdot f_{e_{1} e_{1}}^{\prime \prime}+\delta \cdot v_{g g}^{\prime \prime} \cdot g_{e_{1}}^{\prime} \cdot g_{e_{1}}^{\prime}+\delta \cdot v_{g}^{\prime} \cdot g_{e_{1} e_{1}}^{\prime \prime}-C_{1}^{\prime \prime} \\
& +\delta \cdot\left(v_{g g}^{\prime \prime} \cdot g_{e_{2}}^{\prime} \cdot g_{e_{1}}^{\prime}+v_{g}^{\prime} \cdot g_{e_{1} e_{2}}^{\prime \prime}\right) \cdot \frac{d e_{2}^{*}}{d e_{1}} \\
\geq & u_{f f}^{\prime \prime} \cdot\left(f_{e_{1}}^{\prime}\right)^{2}+\frac{f_{e_{1}}^{\prime}}{f_{a}^{\prime}} \cdot u_{f}^{\prime} \cdot f_{e_{1} a}^{\prime \prime} \longleftrightarrow \\
& u_{f}^{\prime} \cdot f_{e_{1} e_{1}}^{\prime \prime}+\delta \cdot v_{g g}^{\prime \prime} \cdot g_{e_{1}}^{\prime} \cdot g_{e_{1}}^{\prime}+\delta \cdot v_{g}^{\prime} \cdot g_{e_{1} e_{1}}^{\prime \prime}-C_{1}^{\prime \prime}+\delta \cdot\left(v_{g g}^{\prime \prime} \cdot g_{e_{2}}^{\prime} \cdot g_{e_{1}}^{\prime}+v_{g}^{\prime} \cdot g_{e_{1} e_{2}}^{\prime \prime}\right) \cdot \frac{d e_{2}^{*}}{d e_{1}} \\
\geq & \frac{f_{e_{1}}^{\prime}}{f_{a}^{\prime}} \cdot u_{f}^{\prime} \cdot f_{e_{1} a}^{\prime \prime} \longleftrightarrow \\
& \left(u_{f}^{\prime} \cdot f_{e_{1} e_{1}}^{\prime \prime}-\frac{f_{e_{1}}^{\prime}}{f_{a}^{\prime}} \cdot u_{f}^{\prime} \cdot f_{e_{1} a}^{\prime \prime}\right)+\delta \cdot v_{g g}^{\prime \prime} \cdot g_{e_{1}}^{\prime} \cdot g_{e_{1}}^{\prime}+\delta \cdot v_{g}^{\prime} \cdot g_{e_{1} e_{1}}^{\prime \prime}-C_{1}^{\prime \prime}+ \\
& \delta \cdot\left(v_{g g}^{\prime \prime} \cdot g_{e_{2}}^{\prime} \cdot g_{e_{1}}^{\prime}+v_{g}^{\prime} \cdot g_{e_{1} e_{2}}^{\prime \prime}\right) \cdot \frac{d e_{2}^{*}}{d e_{1}} \geq 0 \longleftrightarrow \\
& u_{f}^{\prime} \cdot\left(f_{e_{1} e_{1}}^{\prime \prime}-\frac{f_{e_{1}}^{\prime}}{f_{a}^{\prime}} \cdot f_{e_{1} a}^{\prime \prime}\right)+\delta \cdot v_{g g}^{\prime \prime} \cdot g_{e_{1}}^{\prime} \cdot\left(g_{e_{1}}^{\prime}+g_{e_{2}}^{\prime} \cdot \frac{d e_{2}^{*}}{d e_{1}}\right)+\delta \cdot v_{g}^{\prime}\left(g_{e_{1} e_{1}}^{\prime \prime}+g_{e_{1} e_{2}}^{\prime \prime} \cdot \frac{d e_{2}^{*}}{d e_{1}}\right)-C_{1}^{\prime \prime} \\
\geq & 0
\end{aligned}
$$

But this yields the wanted contradiction since each term on the left-hand side of the expression is negative, 
which can be seen by evaluating them separately:

$$
\begin{array}{ll}
u_{f}^{\prime} \cdot\left(f_{e_{1} e_{1}}^{\prime \prime}-\frac{f_{e_{1}}^{\prime}}{f_{a}^{\prime}} \cdot f_{e_{1} a}^{\prime \prime}\right)<0 & \text { since } f_{e_{1} e_{1}}^{\prime \prime}<0 \text { and } f_{e_{1} a}^{\prime \prime} \geq 0, \\
\delta \cdot v_{g g}^{\prime \prime} \cdot g_{e_{1}}^{\prime} \cdot\left(g_{e_{1}}^{\prime}+g_{e_{2}}^{\prime} \cdot \frac{d e_{2}^{*}}{d e_{1}}\right)<0 & \text { from } E q \cdot(1.5), \\
\delta \cdot v_{g}^{\prime}\left(g_{e_{1} e_{1}}^{\prime \prime}+g_{e_{1} e_{2}}^{\prime \prime} \cdot \frac{d e_{2}^{*}}{d e_{1}}\right)<0 & \text { since } g_{e_{1} e_{1}}^{\prime \prime}<0 \text { and } \frac{d e_{2}^{*}}{d e_{1}}<0, \\
C_{1}^{\prime \prime}>0 . &
\end{array}
$$

Thus, $\partial e_{1}^{*}(a) / \partial a<0$ implies $d f(a) / d a>0$.

\subsubsection{Proofs for Section 5.4}

Proof of Proposition 3. We begin with (i). Writing $\partial g\left(e_{1}, e_{2}\right) / \partial a$ in reduced form yields:

$$
\frac{\partial g\left(e_{1}, e_{2}\right)}{\partial a}=\frac{\partial g\left(e_{1}(a), e_{2}\left(e_{1}(a)\right)\right)}{\partial a}=\frac{\partial g}{\partial e_{1}} \frac{\partial e_{1}}{\partial a}+\frac{\partial g}{\partial e_{2}} \frac{\partial e_{2}}{\partial e_{1}} \frac{\partial e_{1}}{\partial a}
$$

Hence, we need to show that

$$
\frac{\partial g}{\partial e_{1}} \frac{\partial e_{1}}{\partial a}+\frac{\partial g}{\partial e_{2}} \frac{\partial e_{2}}{\partial e_{1}} \frac{\partial e_{1}}{\partial a}<0
$$

or equivalently,

$$
\frac{\partial e_{1}}{\partial a}\left(\frac{\partial g}{\partial e_{1}}+\frac{\partial g}{\partial e_{2}} \frac{\partial e_{2}}{\partial e_{1}}\right)<0
$$

But this follows directly from Propositions 1 and 2(ii).

Next we prove (ii). Players that refrain from participating in the elite program have senior effort $e_{2}=0$. By assumption, we have $g\left(e_{1}, 0\right)=0$. Thus, players born sufficiently late in the year have the lowest possible senior quality (of zero).

\subsection{Appendix C: The Silverman test and measures of skewness}

\section{The Silverman test}

The mode (or peak) of a continuous probability distribution is the value at which its probability density function (pdf) obtains its maximum value. The mode is not necessarily unique. When the pdf has multiple local maxima points it is common to refer to all (local) maxima points as modes, in which case the distribution is called multimodal (as opposed to unimodal). A bimodal distribution has two modes.

Silverman (1981) developed a non-parametric (i.e., free of any assumption on the distribution of the data) test of the number of modes of a pdf. We use this test to test the following hypothesis:

$\mathrm{H}_{0}$ : The probability distribution function is unimodal,

$\mathrm{H}_{1}$ : The probability distribution function is at least bimodal (i.e., multimodal).

Hall and York (2001) developed a testing procedure that has better power than the original test and the correct asymptotic level. They proposed a bootstrap procedure to mimic the asymptotic distribution of the test statistic under the null. We used the $\mathrm{R}$ package silvermantest to implement the Silverman test with Hall and York's (2001) bootstrap procedure. 


\section{Measures of skewness}

The conventional measure of skewness (called "Standard" in Table 3) is given by $E\left(\left(y_{t}-\mu\right) / \sigma\right)^{3}$ where $\Omega=\left\{y_{1}, \ldots, y_{N}\right\}$ is a set of $N$ i.i.d observations, $\mu=E\left(y_{t}\right)$ is the mean and $\sigma=\sqrt{E\left(y_{t}-\mu\right)^{2}}$ is the standard deviation. Due to the third power term, it is well-known that this measure can be arbitrarily large when there are one or more outliers in the data $\Omega$. Thus, it can be difficult to judge whether the measure is large or there exist some outliers in the data. For this reason, more robust measures to outliers have been proposed. These measures of skewness are based on that the median and interquantile range are more robust measures of location and dispersion than the mean and standard deviation (See Kim and White, 2004, for a more detailed discussion).

Let $Q_{1}, Q_{2}$ and $Q_{3}$ be the first, second (median) and third quartiles of the data $\Omega$. In addition to the "Standard" measure in Section 3, we consider the Bowley measure: $\left(Q_{3}+Q_{1}-2 Q_{2}\right) /\left(Q_{3}-Q 1\right)$, the Groeneveld \& Meeden measure: $\left(\mu-Q_{2}\right) / E\left(\left|y_{t}-Q_{2}\right|\right)$ and the Pearson measure: $\left(\mu-Q_{2}\right) / \sigma$. 


\section{References}

Ackerman, P. L. (2014). Nonsense, common sense, and science of expert performance: Talent and individual differences", Intelligence, 45, 6-17.

Aiyagari, S. R., Greenwood, J. and Seshadri, A. (2002). Efficient investment in children. Journal of Economic Theory, 201(2), 290-321.

Angrist, J. D. and Krueger, A. B. (1992). The Effect of Age at School Entry on Educational Attainment: An Application of Instrumental Variables with Moments from Two Samples. Journal of the American Statistical Association, 87, 328-336.

Ashworth, J., and Heyndels, B. (2007). Selection Bias and Peer Effects in Team Sports The Effect of Age Grouping on Earnings of German Soccer Players. Journal of Sports Economics, 8(4), 355-377.

Becker, G. and Tomes, N. (1986). Human Capital and the Rise and Fall of Families. Journal of Labor Economics, 4(3), 1-39.

Bénabou, R. (2002). Tax and education policy in a heterogeneous-agent economy: what levels of redistribution maximize growth and efficiency? Econometrica, 70(2), 481-517.

Black, S. E., Devereux, P. J., and Salvanes, K. G. (2011). Too Young to Leave the Nest? The Effects of School Starting Age. The Review of Economics and Statistics, 93(2), 455-467.

Bilalić, M., McLeod P. and Gobet F. (2007). Does chess need intelligence? - A study with young chess players. Intelligence, $35,457-470$.

Bryson, A., Gomez, R., and Zhang, T. (2014). All-star or benchwarmer? Relative age, cohort size and career success in the NHL. IZA Discussion Paper 8645.

Cunha, F. and Heckman J. (2007). The technology of skill formation. American Economic Review, 97(2), $31-47$.

Cunha, F., Heckman J., Lochner L., and Masterov D. (2006). Interpreting the evidence on life cycle skill formation. Handbook of the Economics of Education, 1, 697-812.

Dustmann, C., Puhani, P. A. and Schönberg, U. (2016), The Long-Term Effects of Early Track Choice. Econ J, doi:10.1111/ecoj.12419.

Epple, D., Newton, E., and Romano, R. (2002). Ability tracking, school competition, and the distribution of educational benefits. Journal of Public Economics, 83(1), 1-48.

Ericsson, K.A. (2008). Deliberate practice and acquisition of expert performance: a general overview. Academic emergency medicine,15:1, 988-994.

Ericsson, K.A. (2007). Deliberate practice and the modifiability of body and mind: toward a science of the structure and acquisition of expert and elite performance. Int J Sport Psychol, 38, 4-34.

Ericsson K.A, Krampe R.T. and Tesch-Römer C. (1993). The role of deliberate practice in the acquisition of expert performance. Psychol Rev, 100, 363-406. 
Ericsson K.A. and Pool, R. (2016). Peak: Secrets from the new science of expertise, The Bodley Head, London.

Fredriksson, P. and Öckert, B. (2014). Life-cycle Effects of Age at School Start. The Economic Journal, 124 (579), 977-1004.

Fumarco, L. (2015). Relative Age Effect on Labor Market Outcomes for High-Skilled Workers: Evidence from Soccer. Linnaeus University.

Gibbs, B. G., Jarvis, J. A., and Dufur, M. J. (2012). The Rise of the Underdog? The Relative Age Effect Reversal Among Canadian-Born NHL Hockey Players: A Reply to Nolan and Howell. International Review for the Sociology of Sport, 47(5), 644-649.

Kim, T.-H. and White, H. (2004). On more robust estimation of skewness and kurtosis. Finance Research Letters, 1, 56-73.

Lazear, E. (2001). Educational Production. Quarterly Journal of Economics, Vol. 116, No 3, 777-803.

Morgan, J. and Triebs, T. and Tumlinson, J. (2013). The (Un)Level Playing Field: How Color-Blind Educational Tracking Leads to Unequal Access. Available at SSRN: https://ssrn.com/abstract=2266242 or http://dx.doi.org/10.2139/ssrn.2266242

Musch, J., and Grondin, S. (2001). Unequal Competition as an Impediment to Personal Development: A Review of the Relative Age Effect in Sport. Development Review, 21(2), 147-167.

Smith, J. (2013, December 13), "What Common Dream Jobs Actually Pay", Forbes Magazine.

Tucker, R., and Collins, M. (2012). "What makes champions? A review of the relative contribution of genes and training to sporting success. British Journal of Sports Medicine, 46(8), 555-561.

Vestberg, T., Gustafson, R., Maurex, L., Ingvar, M. and Petrovic, P. (2012) Executive Functions Predict the Success of Top-Soccer Players. PLoS ONE 7(4): e34731. 